\title{
Green and Sustainable Separation of Natural Products from Agro-Industrial Waste: Challenges, Potentialities, and Perspectives on Emerging Approaches
}

\author{
Vânia G. Zuin ${ }^{1,2}$ ( Luize Z. Ramin ${ }^{1}$
}

Received: 30 August 2017 / Accepted: 26 December 2017 / Published online: 17 January 2018 (C) The Author(s) 2018. This article is an open access publication

\begin{abstract}
New generations of biorefinery combine innovative biomass waste resources from different origins, chemical extraction and/or synthesis of biomaterials, biofuels, and bioenergy via green and sustainable processes. From the very beginning, identifying and evaluating all potentially high value-added chemicals that could be removed from available renewable feedstocks requires robust, efficient, selective, reproducible, and benign analytical approaches. With this in mind, green and sustainable separation of natural products from agro-industrial waste is clearly attractive considering both socio-environmental and economic aspects. In this paper, the concepts of green and sustainable separation of natural products will be discussed, highlighting the main studies conducted on this topic over the last 10 years. The principal analytical techniques (such as solvent, microwave, ultrasound, and supercritical treatments), by-products (e.g., citrus, coffee, corn, and sugarcane waste) and target compounds (polyphenols, proteins, essential oils, etc.) will be presented, including the emerging green and sustainable separation approaches towards bioeconomy and circular economy contexts.
\end{abstract}

Keywords Green and sustainable extraction - Sustainable separation · Green analytical techniques $\cdot$ Biomass waste $\cdot$ Biorefinery $\cdot$ Bioeconomy and circular economy

This article is part of the Topical Collection"Chemistry and Chemical Technologies in Waste Valorization"; editedby Carol Sze Ki Lin.

Vânia G. Zuin

vaniaz@ufscar.br; vania.zuin@york.ac.uk

1 Department of Chemistry, Federal University of São Carlos, Rod. Washington Luís, km 235, São Carlos 13565-905, Brazil

2 Green Chemistry Centre of Excellence, University of York, North Yorkshire YO10 5DD, UK 


\section{Introduction}

Currently, it can be observed that global sustainability challenges are all closely interconnected, such as pollution, climate change, biodiversity loss, poverty, energy, and food security. As stated by Liu et al. [1], only holistic and disruptive approaches integrating various components of human and natural systems are effective in identifying and proposing suitable solutions for these challenges, especially those related to research, development, and innovation (RD\&I) in interdisciplinary and transdisciplinary studies. To exemplify this systemic view, Fig. 1 illustrates the Earth surface that, based on the "Dymaxion map" (the Fuller Projection Map), shows the planet as a continuum without splitting any continents, seas, and oceans, where cycles are integrated through flows of matter, energy, and information [1, 2]. Here, Brazil, China, the Caribbean, and Africa interact across space, time, and organizational levels in many ways. For instance, the expansion of soybean production aggravates deforestation in Brazil, but also provides food and feedstock to China. The food trade between both countries also affects other areas, including the Caribbean and Africa. Dust particles from the Sahara Desert, also increased due to unbalanced agricultural practices, can reach the Caribbean and have an impact on coral reefs and soil fertility, diminishing tourism in this region. In addition, nutrient-rich particles from Africa can reach Brazil, improving its forest productivity.

According to the Director-General of the Food and Agriculture Organization (FAO) of the United Nations [3], after years of progress, world hunger has increased since 2015 . Around $60 \%$ of the world's starving people are from countries affected by conflict and climate change, including northeast Nigeria, Somalia, South Sudan, and Yemen with 20 million people, often suffering extreme climatic events such as droughts and floods. Not surprisingly, some of the FAO's top priorities for the next

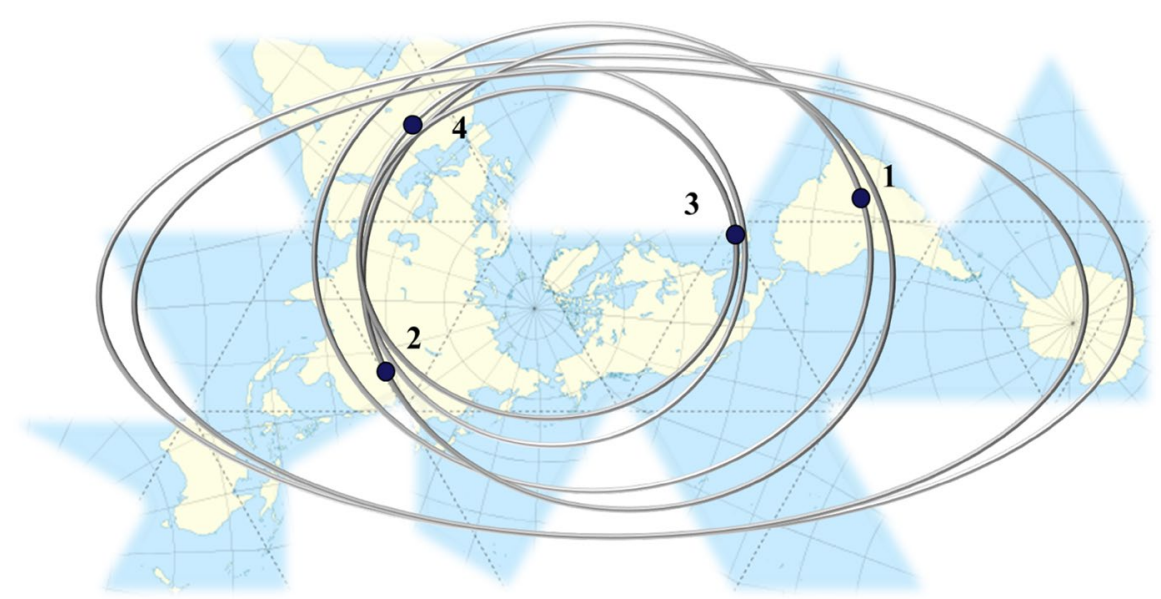

Fig. 1 Representation of an integrated planetary flow system based on the Dymaxion map, emphasizing some coupled cycles related to food production and socio-environmental impacts among (1) Brazil, (2) China, (3) the Caribbean, and (4) the Sahara Desert. Adapted from [1] 
2 years include topics such as sustainable agriculture, climate change mitigation and adaptation, water scarcity and support of subsistence rural practices, and fisheries and forestry $[3,4]$. The challenges related to this demanding context can be intensified and better understood when taking into account that the world population is expected to increase by about $30 \%$ over the next 35 years, reaching more than 9.5 billion people in 2050 and 11.2 billion in 2100 [5].

As pointed out by Xia et al. [6], the global food waste of approximately 1.3 billion tons per year is shocking in this context and, although it should be avoided or minimized, it cannot be completely prevented nowadays. Primary and secondary processing generates unpreventable food supply chain waste. This can be due to a number of factors along the supply chain, differing by the commodity and country in question. In general terms, developing countries such as some African countries suffer the greatest loss during the early, upstream part of the primary processing, corresponding to $75 \%$ of food losses during production and postharvest. Various initiatives, e.g., building better infrastructure through knowledge transfer (more efficient storage and transport technologies) and improving collaboration and market opportunities in the food supply chain could have a positive role. In industrialized countries, waste occurs especially in the consumption stage, accounting for $50 \%$ of overall loss of crops in some countries of North America, Europe, and Oceania. In this case, together with educational and cultural actions, other aspects such as developing legislation to make date labels more user-friendly for consumers (sell-by, best-before, and consume-by), redesigning packaging characteristics (avoiding the "buy 1 get 2" offers) and retailer marketing strategies should be considered [7].

It is estimated that around 140 billion tons of biomass from the agricultural sector are generated every year in the world $[8,9]$, and a considerable part is recognized as waste and not conflicting with food availability, e.g., leaves, roots, stalks, bark, bagasse, straw residues, seeds, wood and animal residues. Using alternative strategies to avoid additional losses and produce several high value-added chemicals could minimize the volume of non-renewable materials used today (i.e., roughly 50 billion tons of fossil fuels), enough to greatly reduce greenhouse gas emissions and dependence on non-sustainable resources. Therefore, considering their available volume and practically low costs locally and globally, associated to rich function, structure and chemical heterogeneity, all agro-industrial waste should also be considered for their chemical and material potential, as well as a source of energy [10-13].

An important proposal related to waste hierarchy as a framework for residue management can be seen in Fig. 2 [14, 15], which was reformulated to include agroindustrial waste. In this case, the agro-industrial waste hierarchy has a different meaning from top to bottom, since all biomass is valued as raw material. 'Prevention' is an intrinsic part of optimized processes, avoiding overproduction. Therefore, the least probable option is 'disposal' as the supply chain is designed to attend sustainable consumption, using all bio-based material generated. Here, sustainable production also includes eco-efficiency, cleaner and green productivity, whereas sustainable consumption allows greener choices to be made by individuals based on eco-procurement, supply chain management, waste minimization, recycling, and resource efficiency measures. Both sustainable production and consumption comprises 'life-cycle thinking', aiming at preventing problems shifting from one 


\section{Prevention}

- Avoid agro-industrial waste generation throughout supply chain (production and consumption)

\section{Reuse}

- Reuse agro-industrial waste via redistribution networks

\section{Recycle}

- Recycle agro-industrial waste into animal feed, composting etc.

\section{Recovery}

- Recover \& valorisation of unavoidable agro-industrial waste to produce chemicals \& energy: extraction via sustainable techniques and / or associated to thermochemical, physico-chemical and bio-chemical conversion

\section{Disposal}

- Ideally, unnecessary, since a biorefinery should be a zero-waste system

Fig. 2 The agro-industrial waste hierarchy modified from [15]. The main idea is to promote sustainable production and consumption systems through zero-waste biorefinery

life-cycle stage to another, one geographical area or environmental compartment to another.

One of the most important and cited references highlighting the advances in genetics, biotechnology, process chemistry, and engineering that has helped establish a new manufacturing concept to convert renewable biomass into valuable fuels and products, known as biorefinery, was published by Ragauskas and collaborators in the mid-2000s [16]. According to these authors and other researchers [16, 17], integrating biomass and biorefinery technologies has the potential to develop sustainable bio-based energy and materials leading to a new manufacturing paradigm (Fig. 3).

In fact, this paradigm is currently connected to other strong concepts, i.e., bioeconomy and circular economy; the latter is described as an industrial system that is restorative by intention and design. This idea replaces the end-of-life notion with regeneration, focusing on the use of renewable energy, elimination of toxic chemicals, reutilization, return and eradication of "waste through the superior design of materials, products, systems, and business models" [18, 19].

As can be noted, new generations of biorefinery combine innovative biomass resources from different origins, chemical extraction and purification and/or synthesis of biomaterials, biofuels and bioenergy via benign processes. From the very beginning, the identification and quantification of all potentially high value-added 


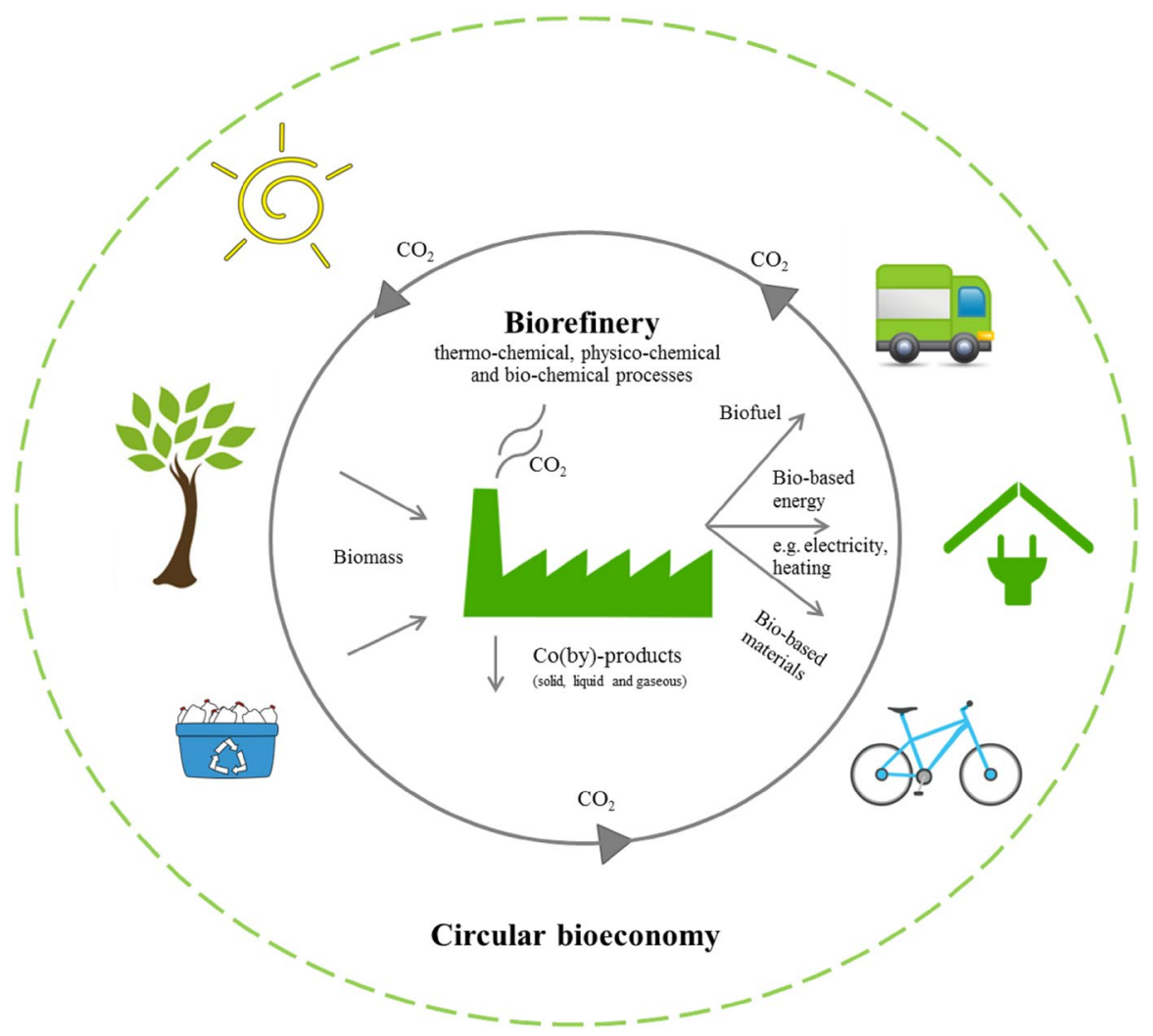

Fig. 3 Holistic biorefinery model integrating biomass, biofuel, biomaterials and bioenergy cycle, based on green and sustainable technologies in the scope of bioeconomy and circular economy. Updated and expanded from $[16,17]$

compounds that could be removed from the available renewable feedstocks requires another analytical approach, also connected to green chemistry [20, 21].

\section{From Green to Sustainable Separation: Towards Holistic, Flexible, and Zero-Waste Biorefineries}

More recently, green extraction and purification have been presented as methods based on establishing processes that reduce energy consumption, using solvents and renewable materials, as well as ensuring a safe and high-quality fraction/product [22]. The aim of their application is to obtain natural products from industrial waste, which is considered a highly attractive initiative [23].

However, a more adequate term for such extraction and purification processes towards vanguard biorefineries could be sustainable separation, adding to the previous green definition, the notion of innovation across all sectors that allows for 
increased value in a wide sense, enhancing human and environment benefits and providing economically accessible technologies also advantageous to industry and large scale processing systems. It includes another dimension related to the generation of more creative and healthy jobs, contributing to the construction of a positive long-term sustainability agenda, encompassing bio-circular economy, environmental and social justice [24-27].

Sustainable separation can be defined as a holistic approach grounded on the circular and flexible design and application of renewable benign materials and auxiliaries (including bio-derived solvents, solid phases, membranes) and processes [rooted on green analytical techniques and sustainability metrics and indices, e.g., life cycle analysis (LCA), chemometrics, and other interdisciplinary indicators]. The aim is to optimize the tuneable use of energy, time, reagents, devices, scale, yield and number of steps to extract, fractionate, purify or even modify the components of interest from bio-derived waste during these in situ processes, ensuring analytical reproducibility, efficiency, selectivity robustness and scalability, with online evaluation regarding measurable objectives to create safer, healthier, and more efficient products, processes, and services under fair conditions, commercially available at accessible and just prices [28-30].

Natural products are among the most attractive value-added chemicals to be considered, which can be classified as organic compounds formed by living systems divided into three main categories: (1) compounds that occur in all cells and have a central role in their metabolism and reproduction (nucleic acids, amino acids, and sugars), also known as primary metabolites; (2) high-molecular polymeric materials which form cellular structures (cellulose, lignins, and proteins) and; (3) chemicals which are characteristic of a limited number of species, called secondary metabolites [22, 30]. Many of these bioactive compounds (e.g., alkaloids, terpenoids, and phenols) have been extensively used as medicine, nutraceuticals, flavors, fragrances, cosmetics, food additives, antimicrobials, bio-pesticides, etc. However, among the biggest challenges for biomass utilization is establishing benign methods to separate, purify and modify it into chemicals, fuels, and new materials. This is partially due to, with rare exceptions, the small amounts which are lower than $0.01 \%$ of the dry weight of vegetal, associated to possible product inhibition issues, large raw material variability, feed detoxification (when necessary), instability of the target compound (or fractions) and its presence in a complex mixture [23, 30].

It is well known that the separation steps, especially extraction, correspond up to $40-80 \%$ of the total costs of most common chemical processes currently used. From the point of view of a holistic biorefinery, separation has attracted more and more attention [31]. For instance, for natural products, solvent-based extraction is one of the best options nowadays considering the nature of many bio-based chemicals and matrices, and also the fact that other separation methods, such as those based on chromatography or membranes, do not have the same advantages taking into account commercial scales [32].

It is expected that high value-added components from biomass waste such as essential oils, polyphenols, and other food or medicinal-related products are extracted first, followed by polysaccharides, lignocelluloses or waxes via advanced separation and depolymerization processes. Among them, green solvents in general, 
supercritical $\mathrm{CO}_{2}$, subcritical water, microwave (MW)-assisted acidolysis and gasexpanded liquids have been mentioned [33]. Green solvents offer important separation advantages, including near-supercritical or supercritical fluids, which have outstanding mass transport properties, polarity, and easiness of solvent removal after extracting the compound of interest [34]. Another interesting solvent is water, but the range of compounds that are soluble in this medium is quite limited. Nevertheless, the use of subcritical water has been demonstrated to be advantageous for organic modification to depolymerize, hydrolyze, gasify, and carbonize biomass to produce bioactive compounds, sugars, biogas, and other valuable solids [16, 35].

Integrating two or more green techniques combining different strategies has played an important role in overcoming the main drawbacks of a single technique towards sustainable separation. For instance, for high-pressure solvent extraction in which the extractants do not reach supercritical conditions, the temperature, time, and solvent consumed can be dramatically reduced associating ultrasound-assisted treatment $[28,36]$. In fact, more attention has been paid to green extraction, purification, or modification of natural products derived from agro-industrial waste nowadays, opening up new opportunities for sustainable approaches designed for bioeconomy and circular economy models. The aim of this paper is to present an overview of the design and application of green and sustainable separation of natural products for vanguard zero-waste biorefineries. The main analytical techniques and procedures described over the last 10 years will be described in detail, showing the potentialities, challenges, and perspectives in this topical and emergent scenario.

\section{High Value-Added Approaches for Green and Sustainable Separation of Natural Products from Waste: What can be Observed from the Literature?}

More recently, trends in green and sustainable extraction, fractionation and purification techniques have largely focused on minimizing the use of solvents, energy and materials that are intrinsically benign to human health and the environment [37]. In order to analyze the status quo and perspectives related to natural product separation from waste, a systematic literature review was conducted using the ISIS Web of Knowledge platform (reviews and papers) from 2006 to 2017, combining the descriptors "natural product" and "green extraction/separation" (or "sustainable extraction/separation" or "eco-friendly extraction/separation") and "waste" (or "residue"). Figure 4 shows the number of publications during this period. There were more than 160 research papers and reviews that, to the best of our knowledge, are reasonably representative to show the strongest tendencies in this field over the last decade. It can be clearly observed that there has been an increase in the number of manuscripts over the last 10 years, covering the principles, advances, and applications of these green methods.

The obtained data reflect the growing interest and potential of green and sustainable methods to separate natural products from waste. One tendency observed in particular was the innovative ways to remove (integrating extraction, purification and/or modification in the same integrated system) and use such compounds in more 


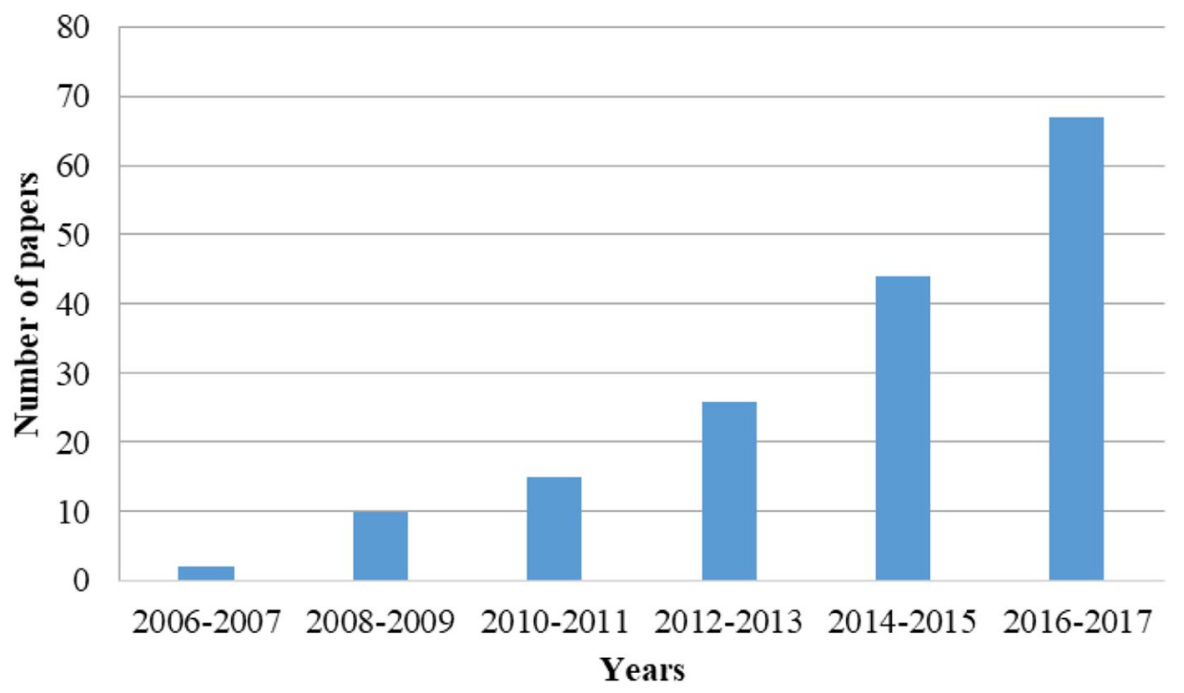

Fig. 4 Number of publications per year focusing on green and sustainable separation (extraction, fractionation and purification) of natural products from waste (ISIS Web of Knowledge, January 2006 to December 2017)

contemporary sectors, promoting human and environmental health instead of general and old-fashioned remediation [19, 38]. As a result, new applications for food, nutraceutical, and agricultural sectors have been further explored, based on their advantageous properties as natural colorants, flavors, aromas, antioxidants, antifungals, bioformulations (bio-pesticides) or simply their use as precursors to generate other compounds for similar uses. Some details related to patents, (non-) clinical trials, sustainable indicators, scaling-up, regulatory, agro-industrial variability and availability, traceability, seasonality, good laboratory and manufacturing practices, additional economical and marketing issues have also been discussed.

Table 1 presents the research papers and reviews published during this period, highlighting their main focus, the green or sustainable techniques/approaches adopted, raw materials (mostly agro-industrial waste) and target compounds studied. The most common raw materials described as chemical feedstocks were waste derived from plants, for instance, food, mainly fruits (citrus, mango, papaya, grape, passiflora, banana, tomato, olive), grains (corn, soybean, sunflower, coffee) and other abundant materials (sugarcane bagasse, tea, wood bark, rice and wheat straw). Additional issues that affect the quality of the final products were also discussed, namely the procedure used for waste collection, selection, storage, drying, matrix characteristics (particle size, shape, specific surface area and porosity). The latter aspects play an important role in extraction efficiency due to the mass and heat transfer processes. Understanding the nature of raw material is crucial to avoid negative influences impacting the quality and yield during the removal of the target compounds, e.g., caused by co-extracted contaminants or due to the presence of some 


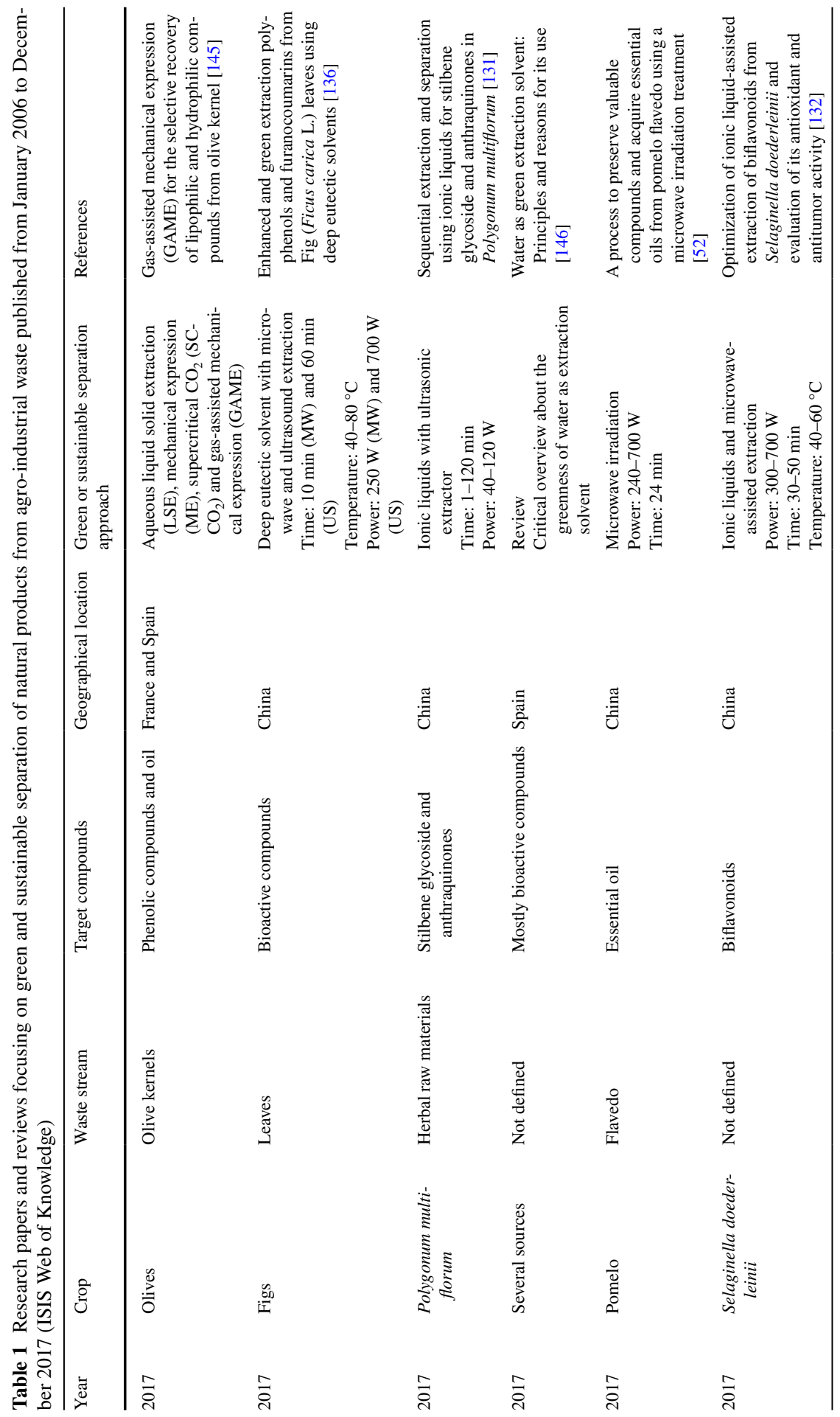




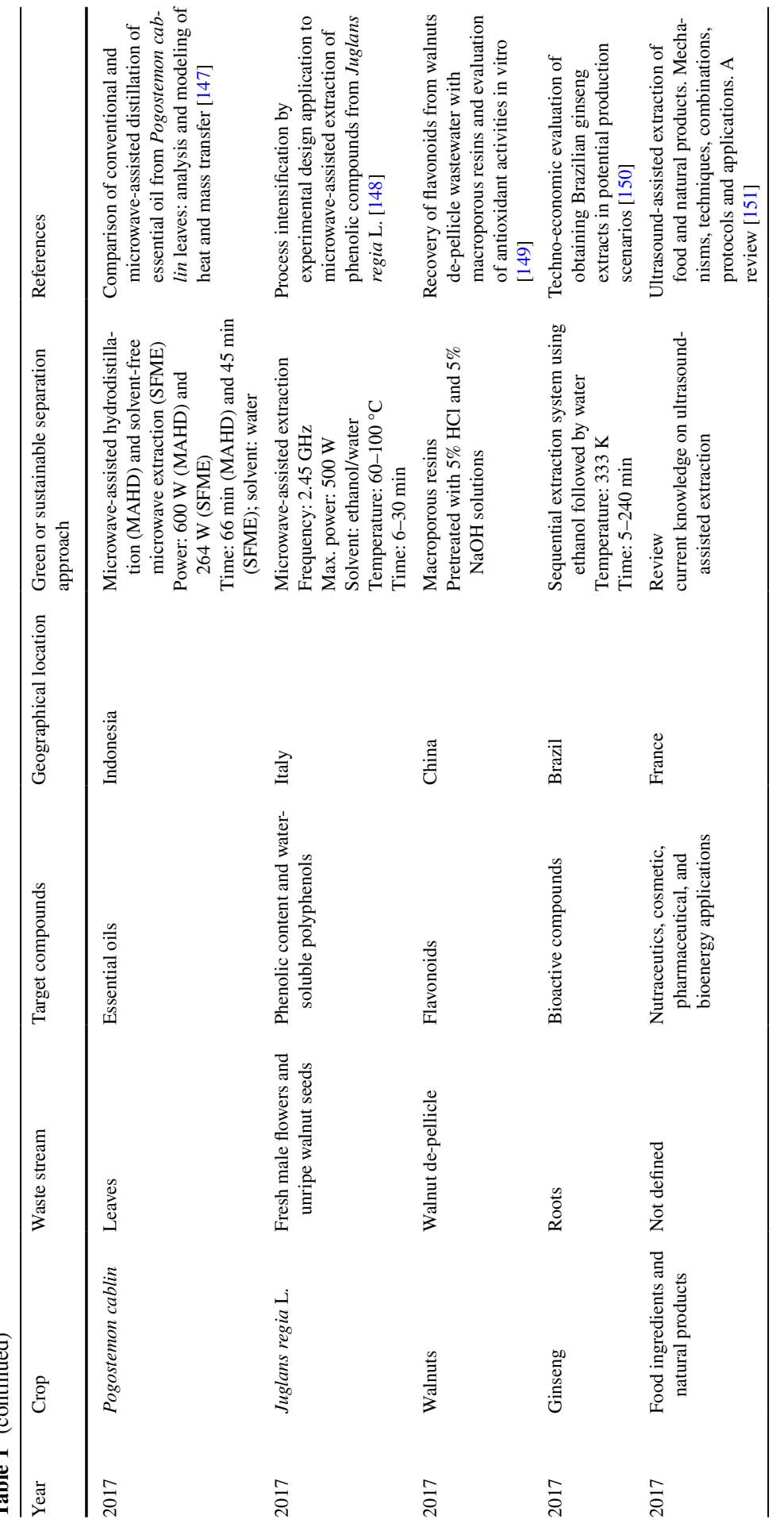




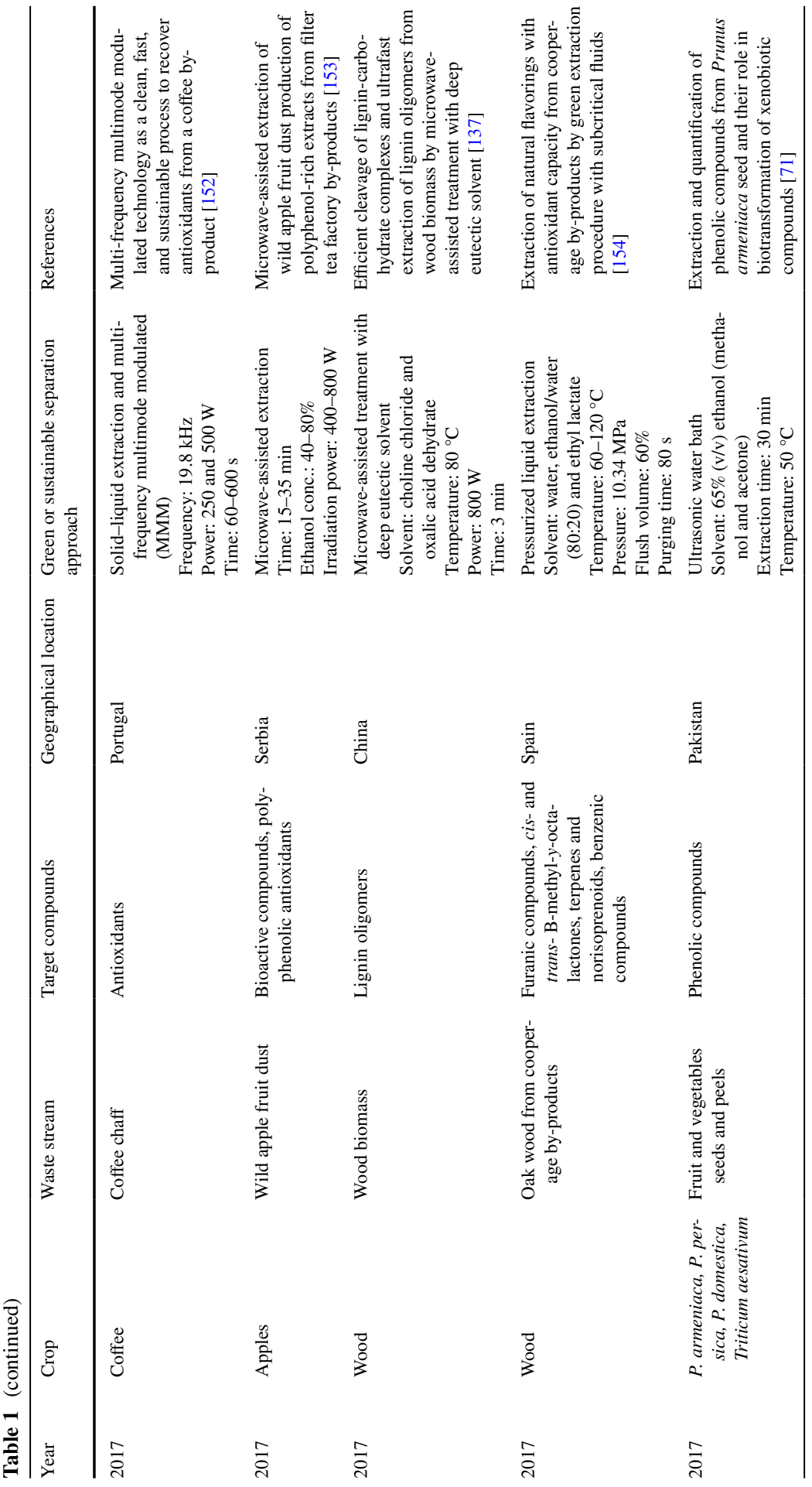




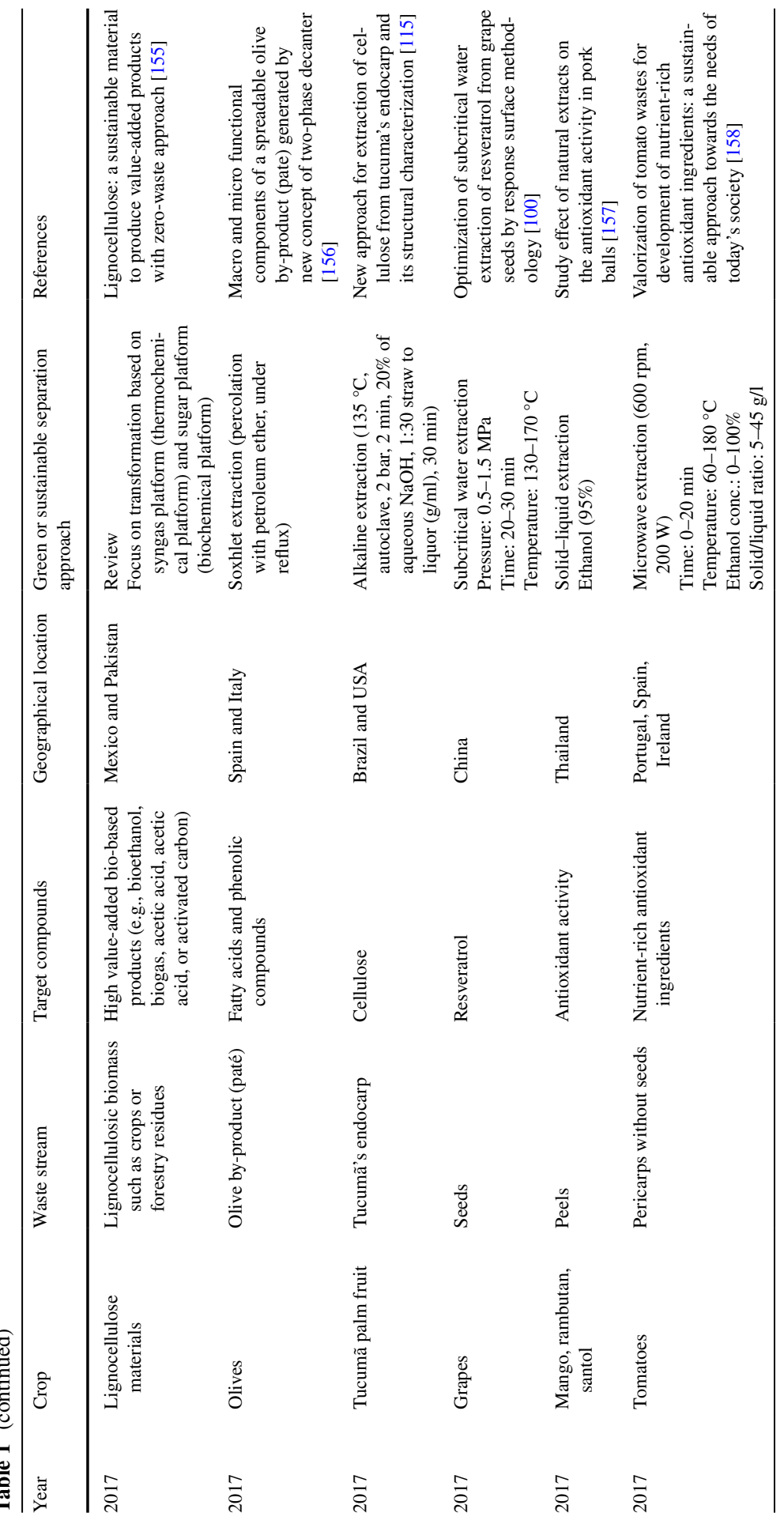




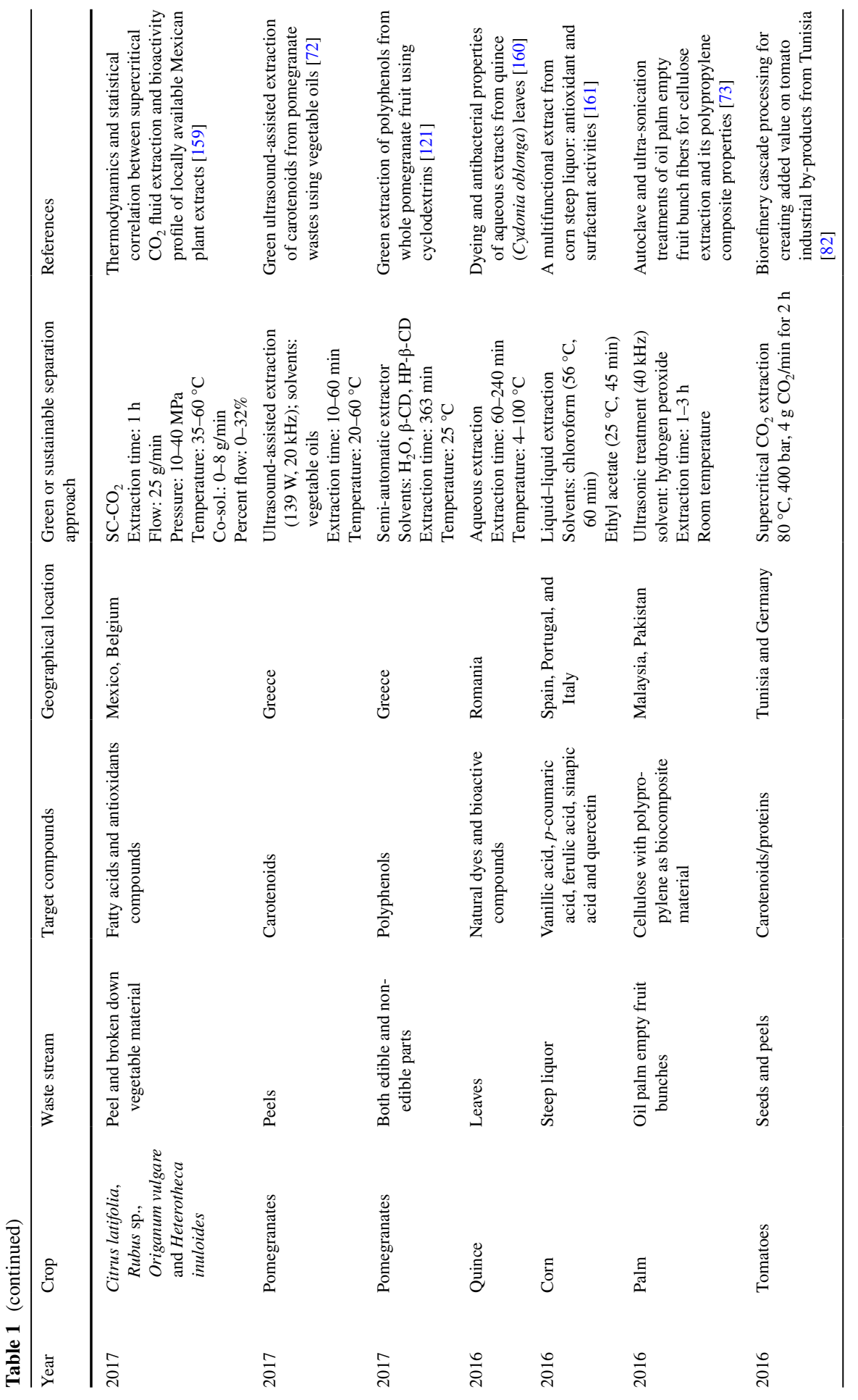




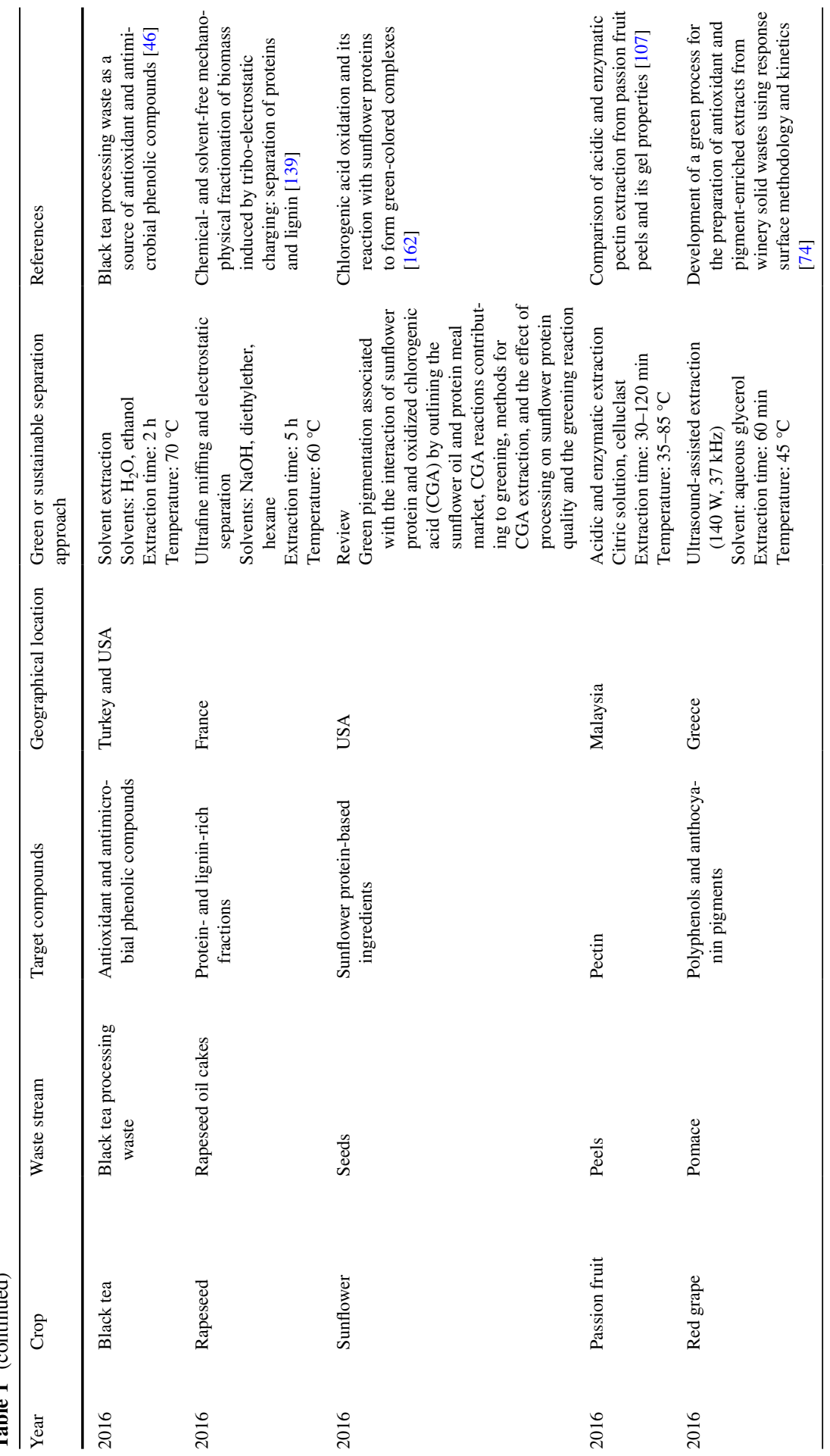




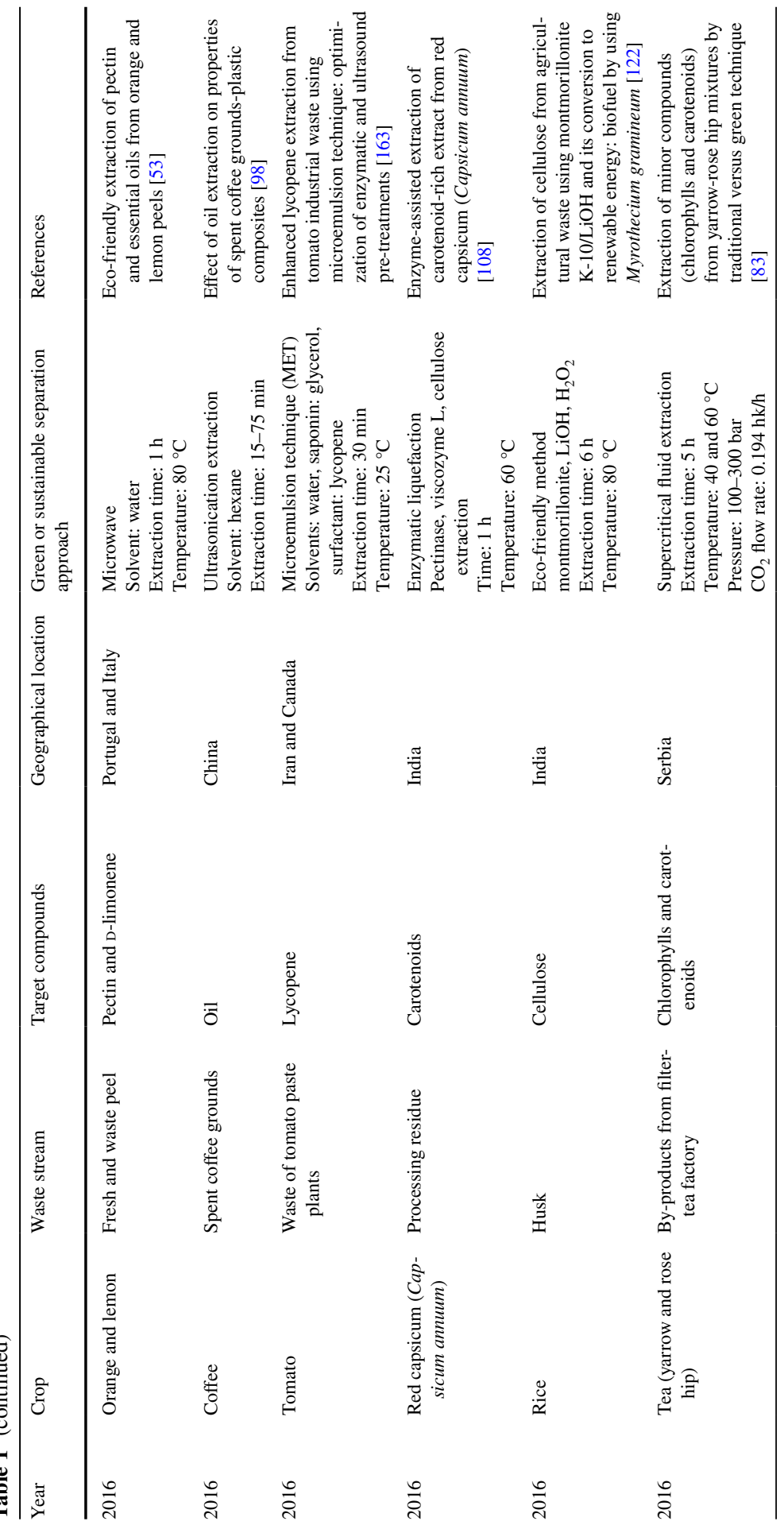




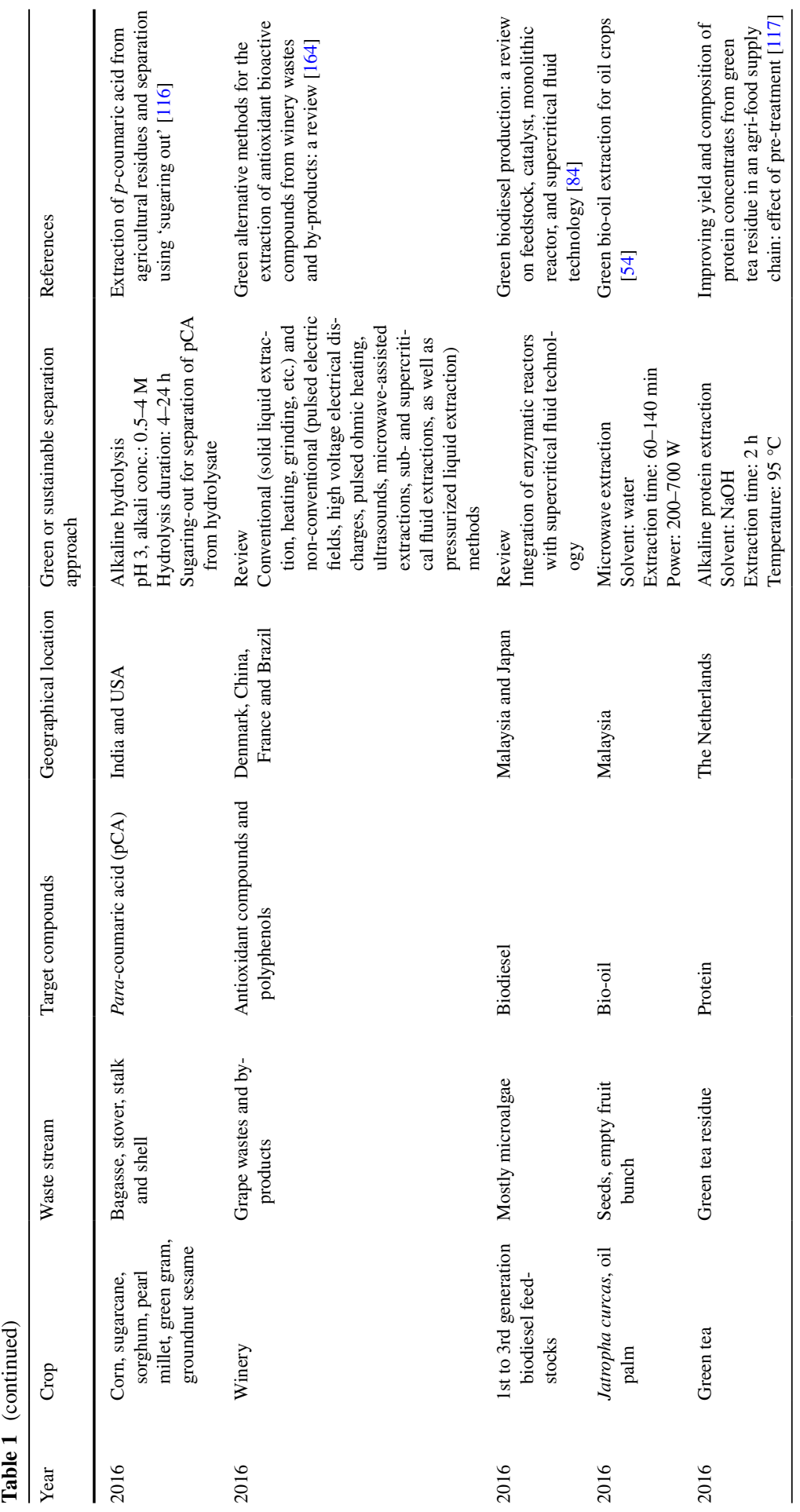




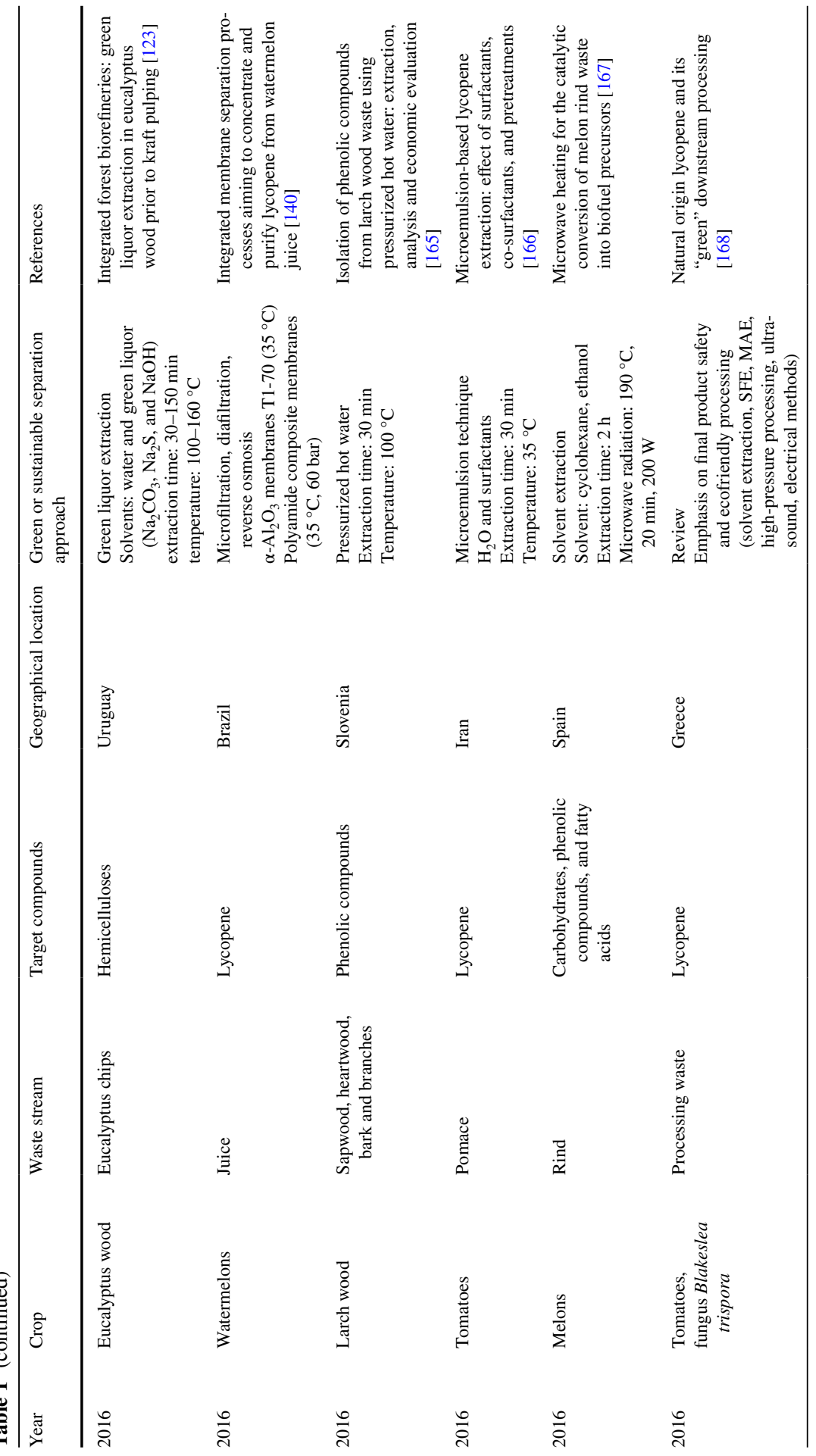




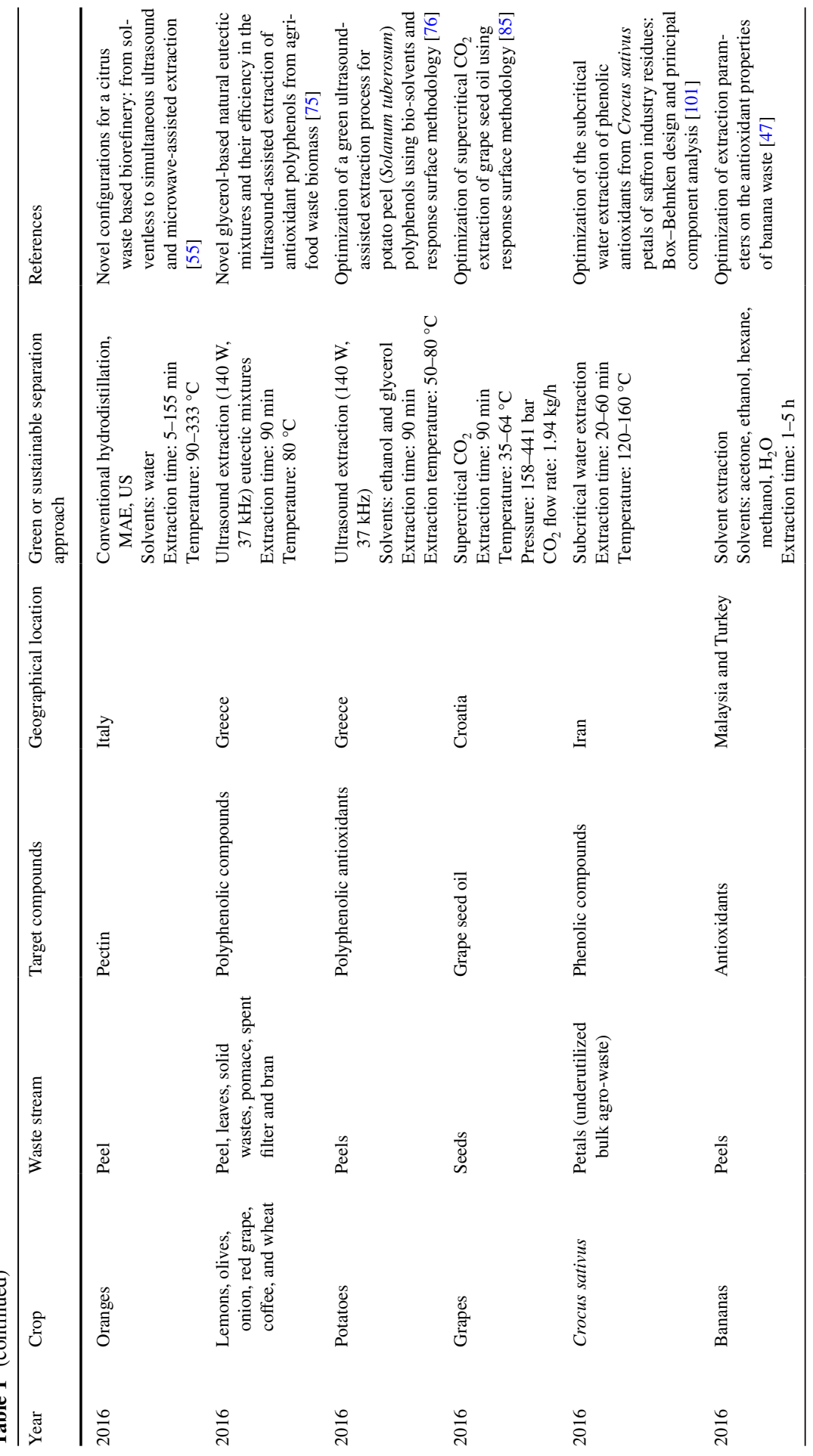




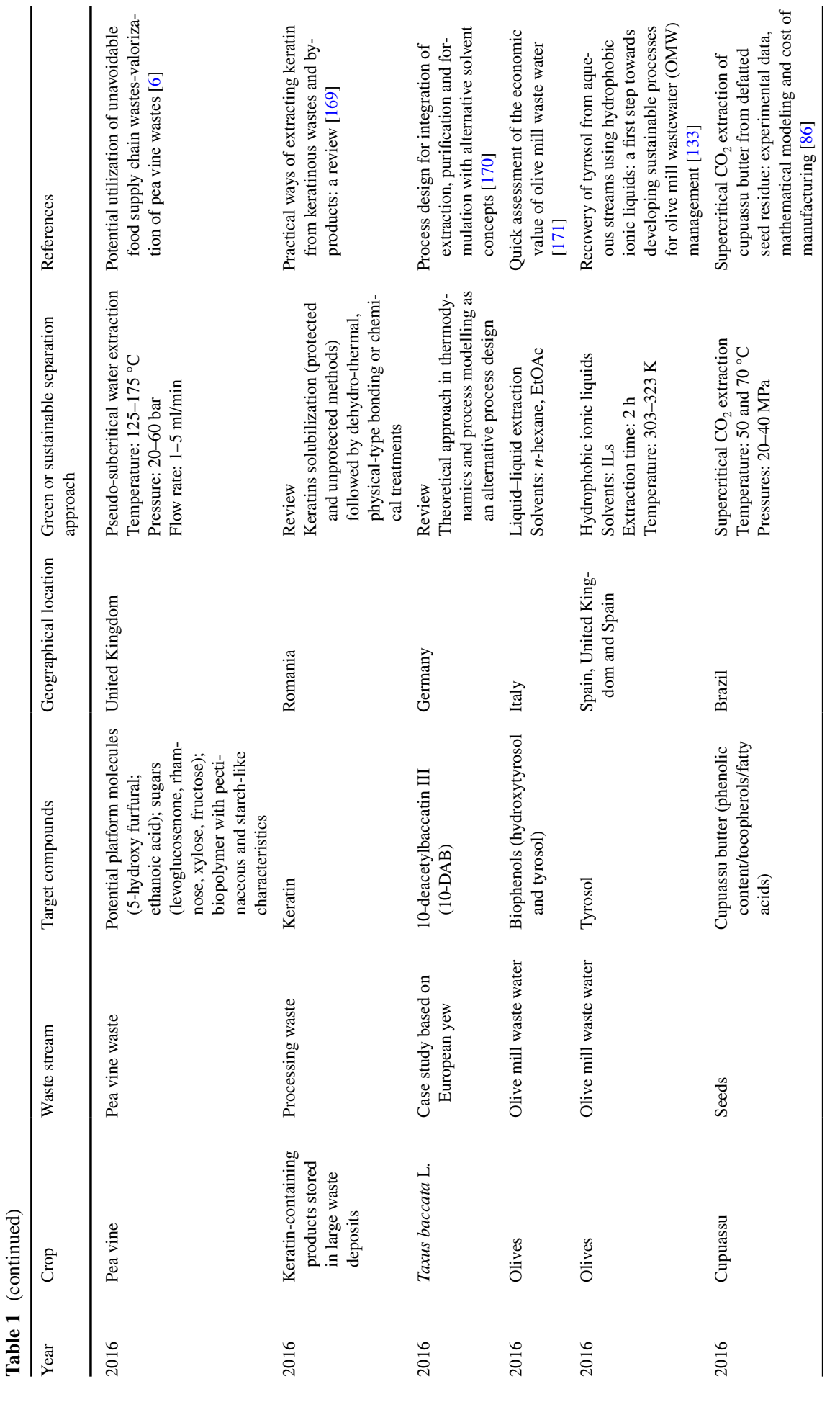




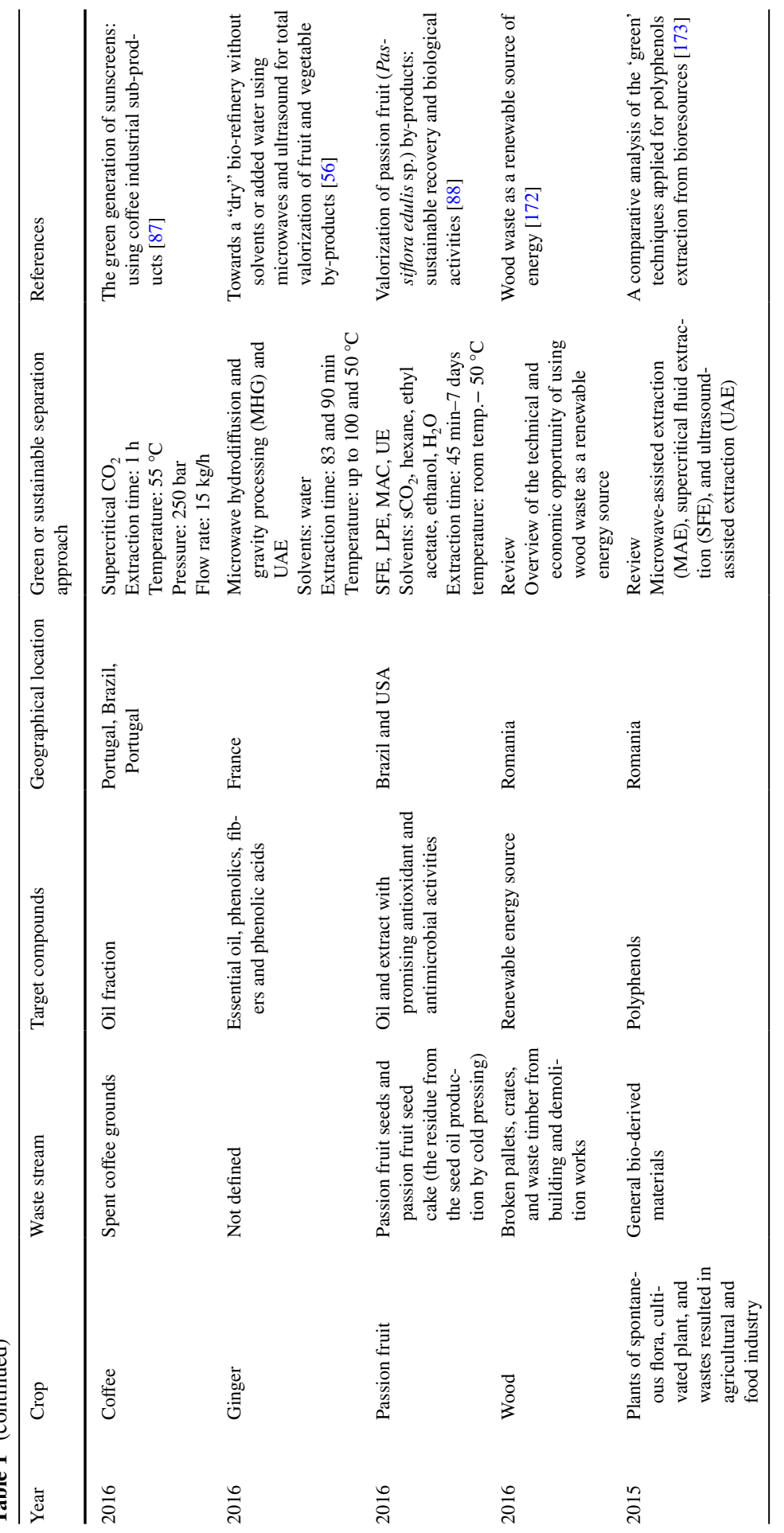




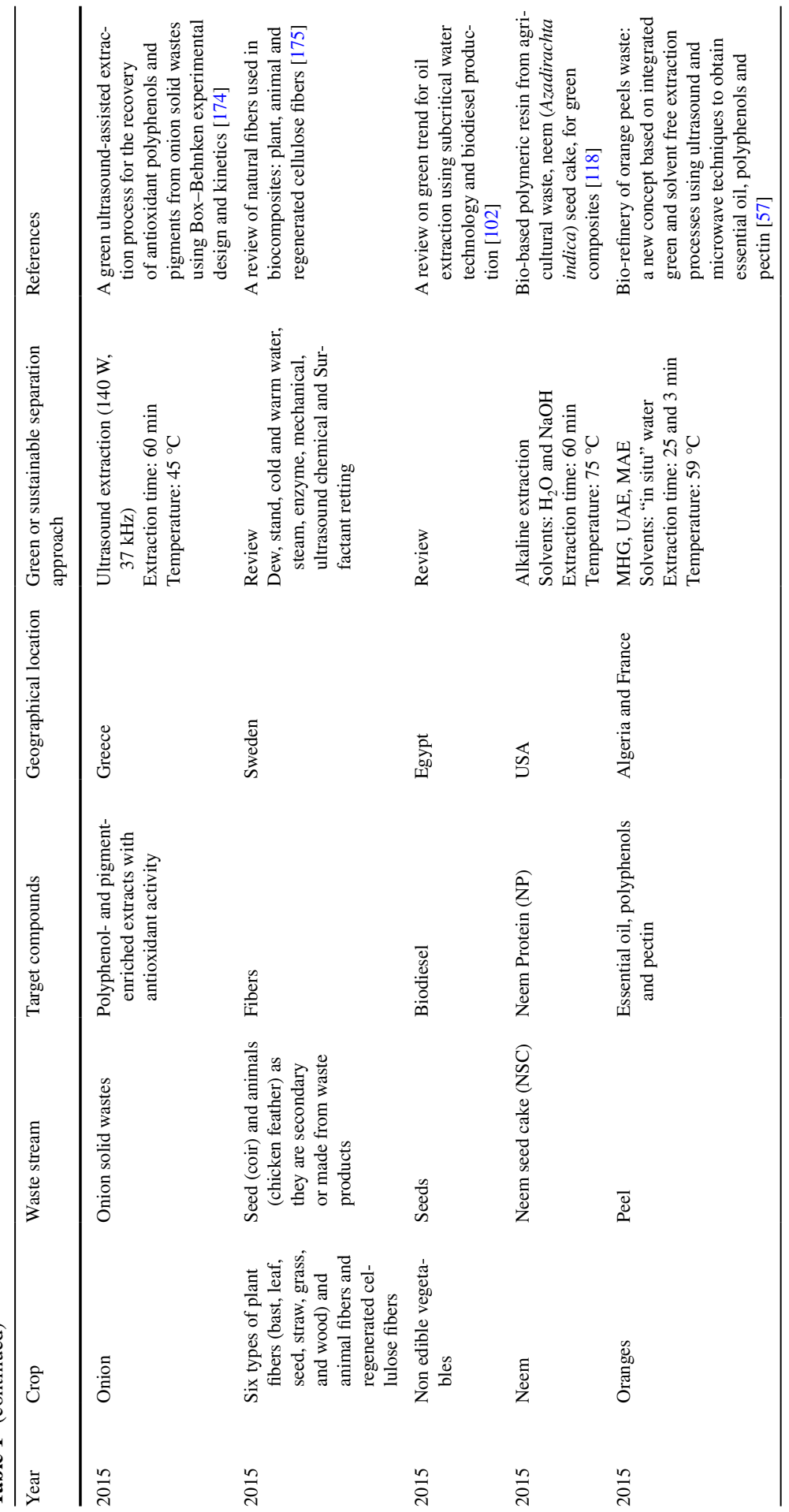




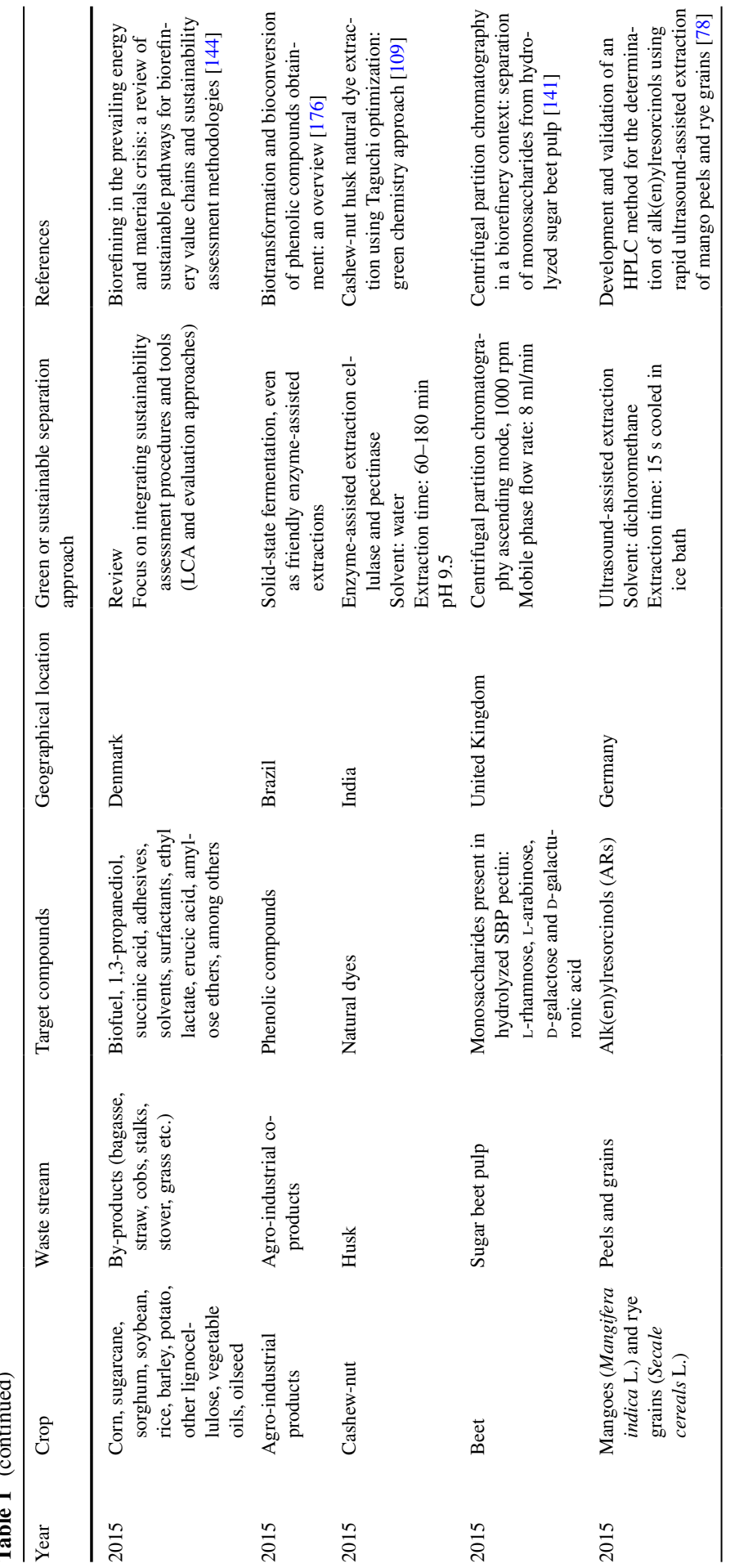




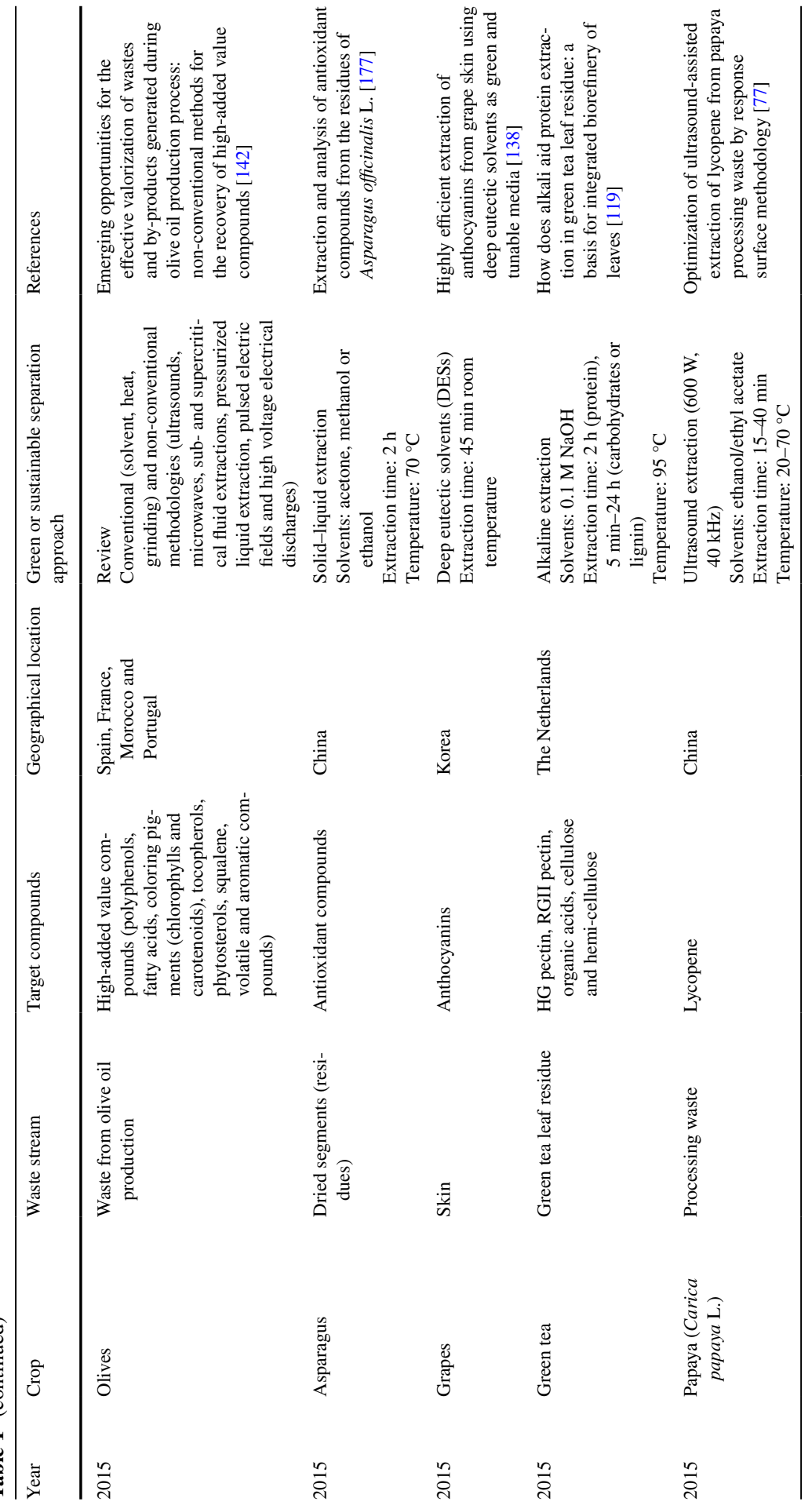




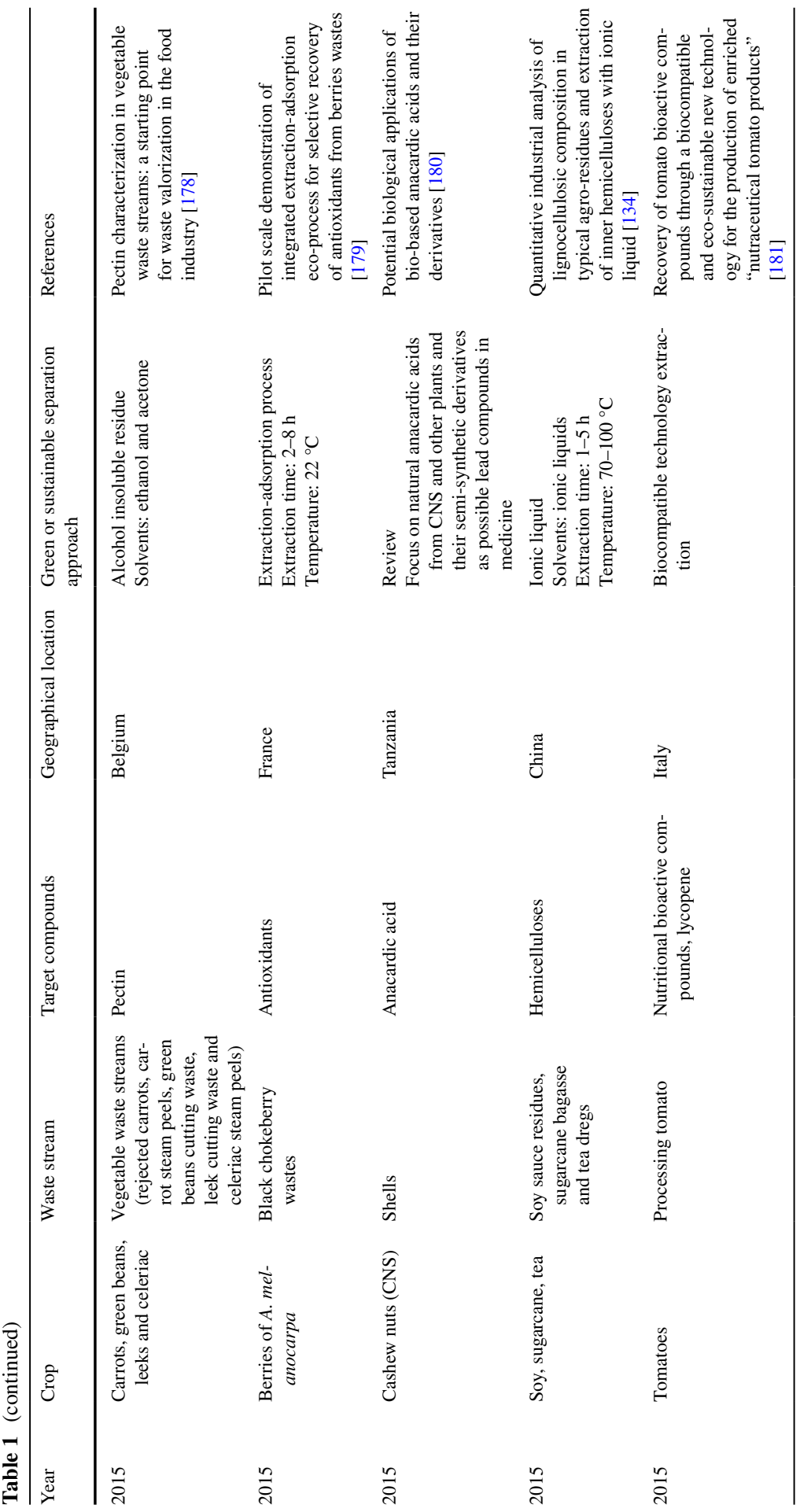




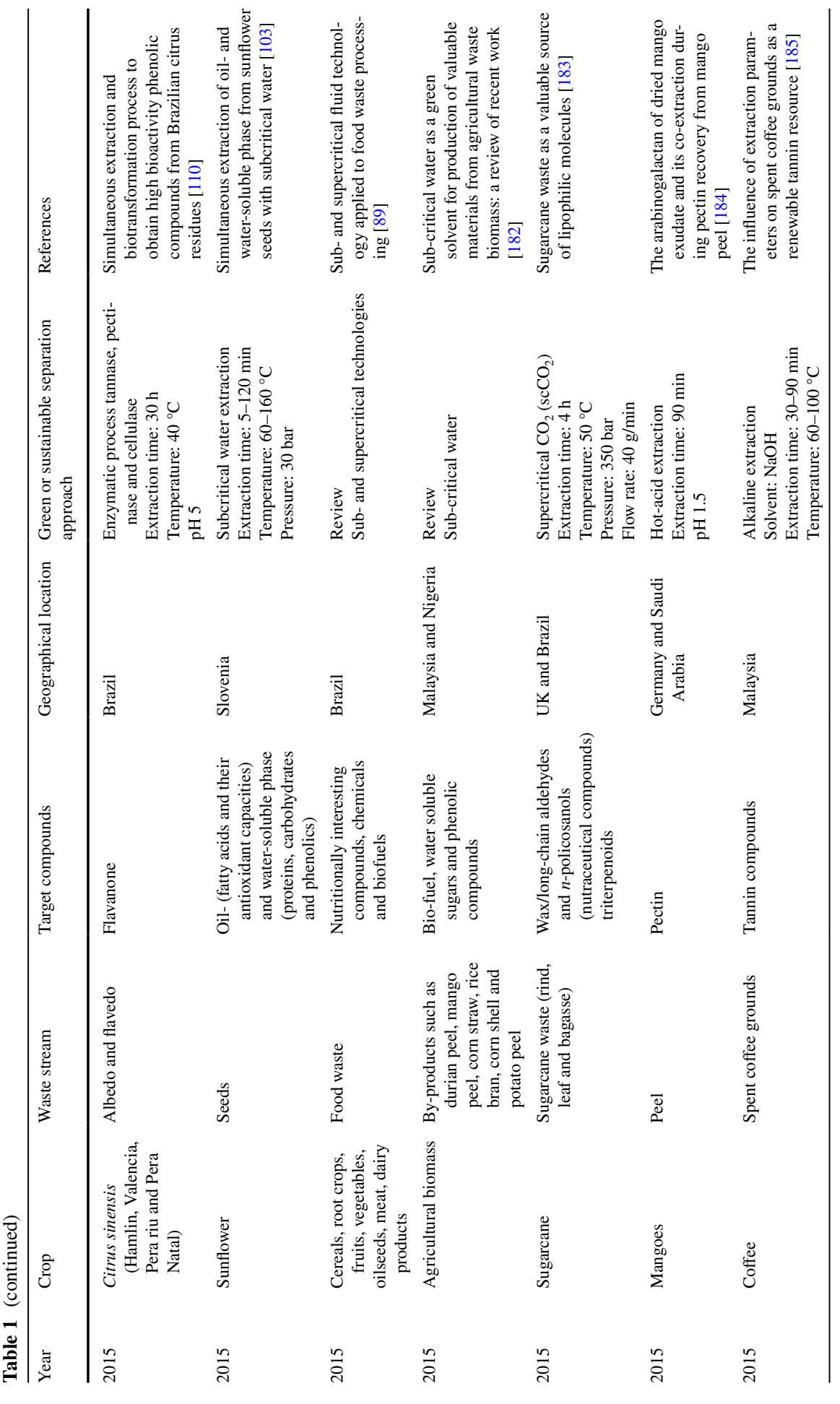




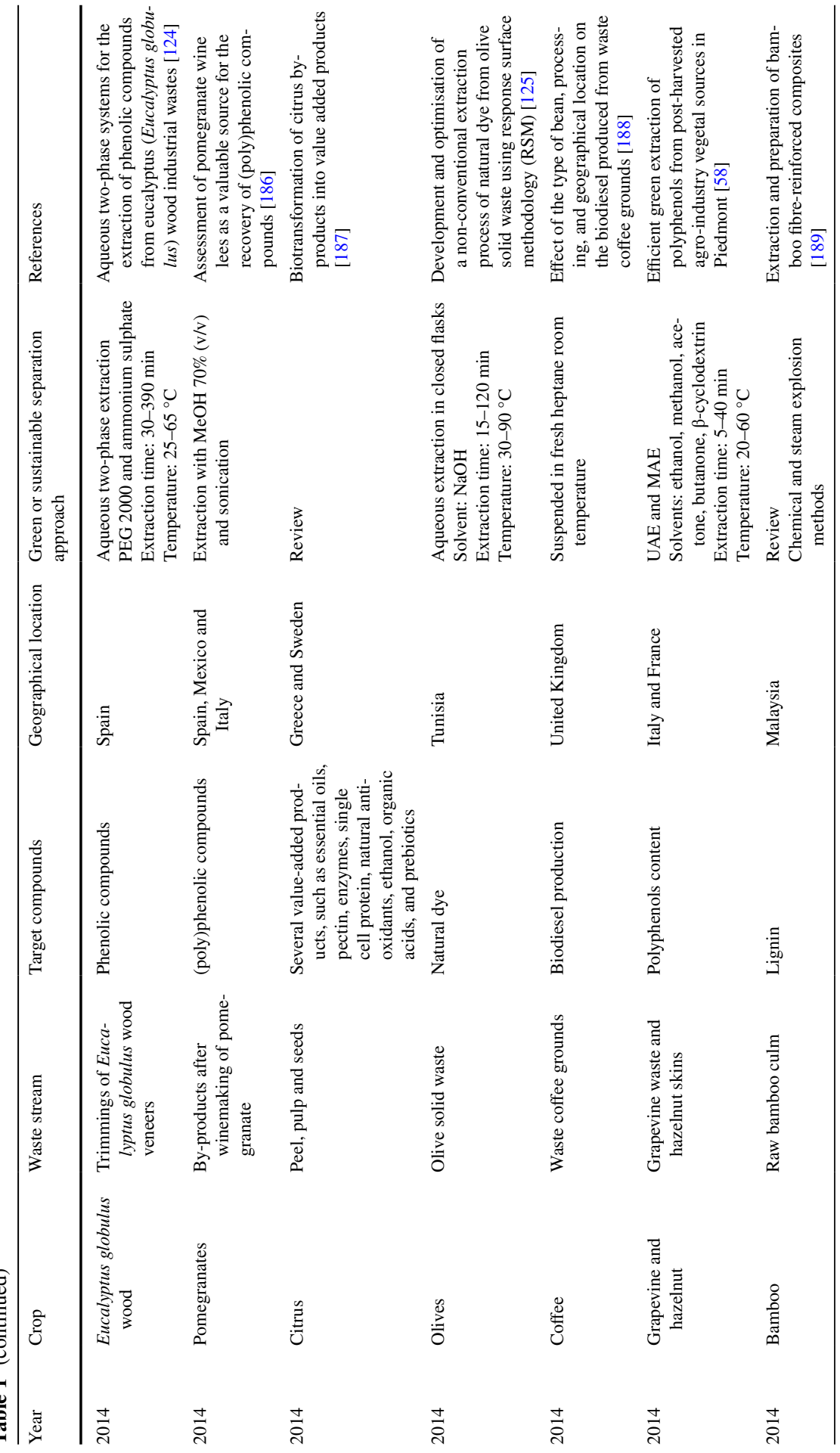




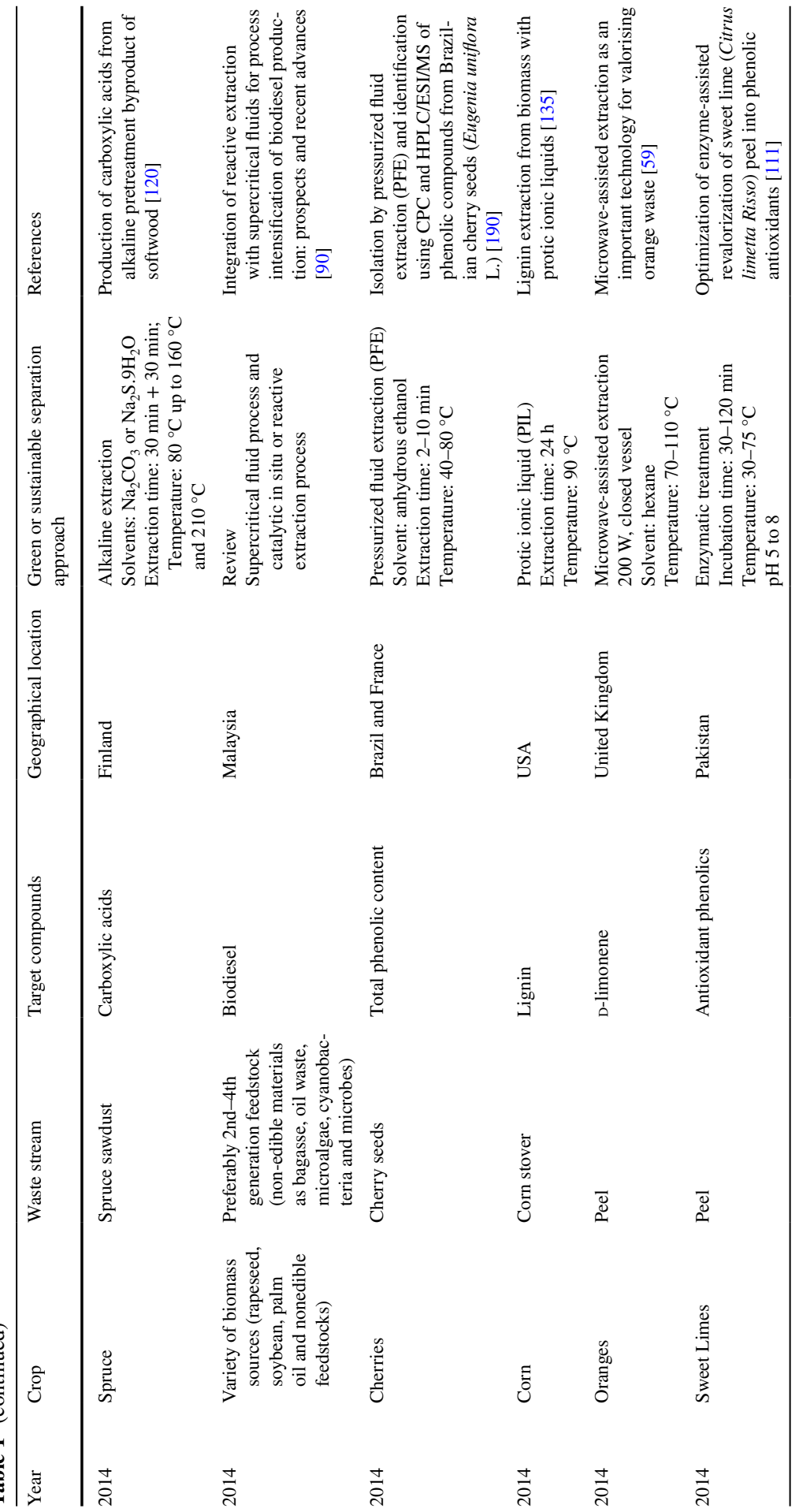




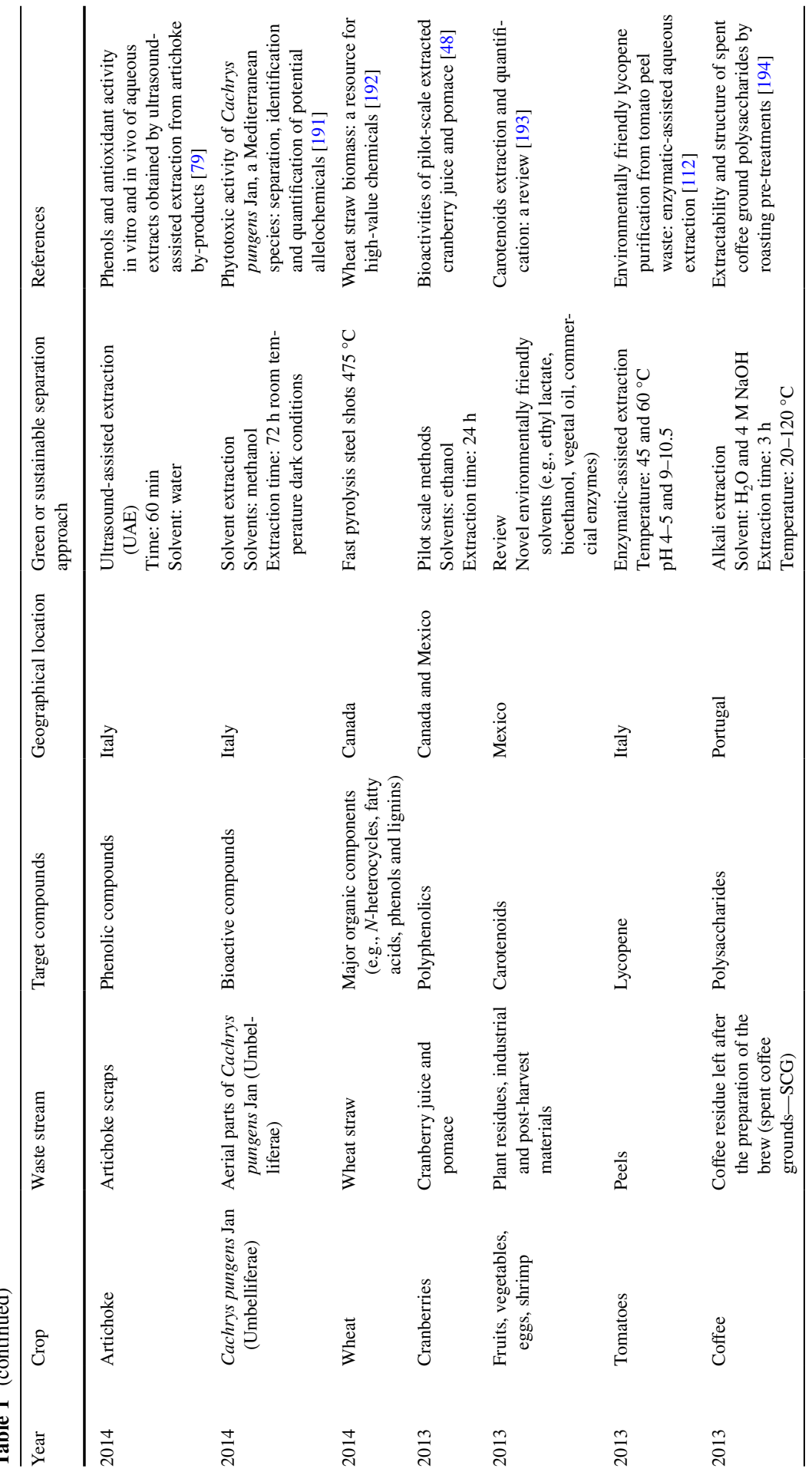




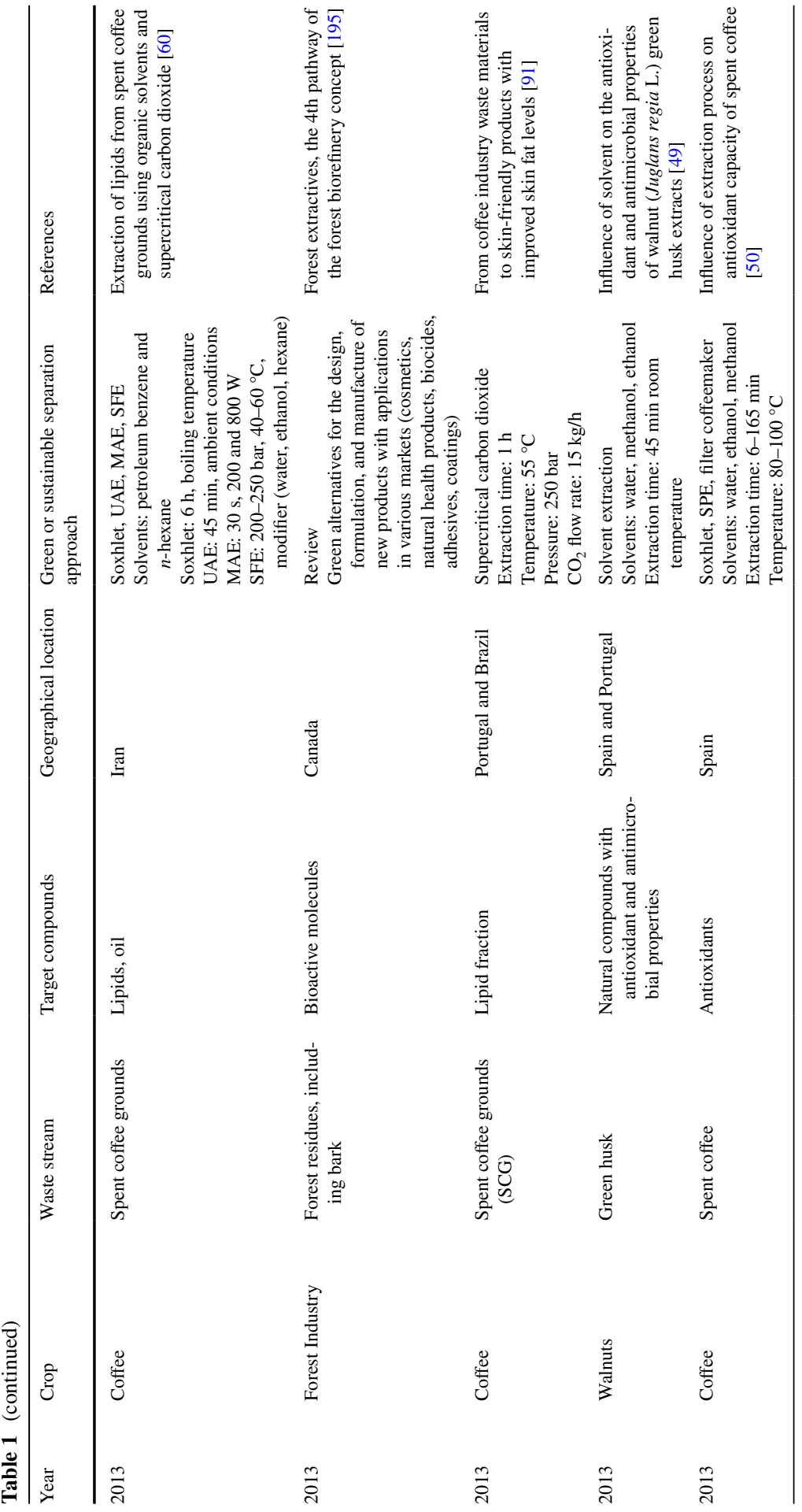




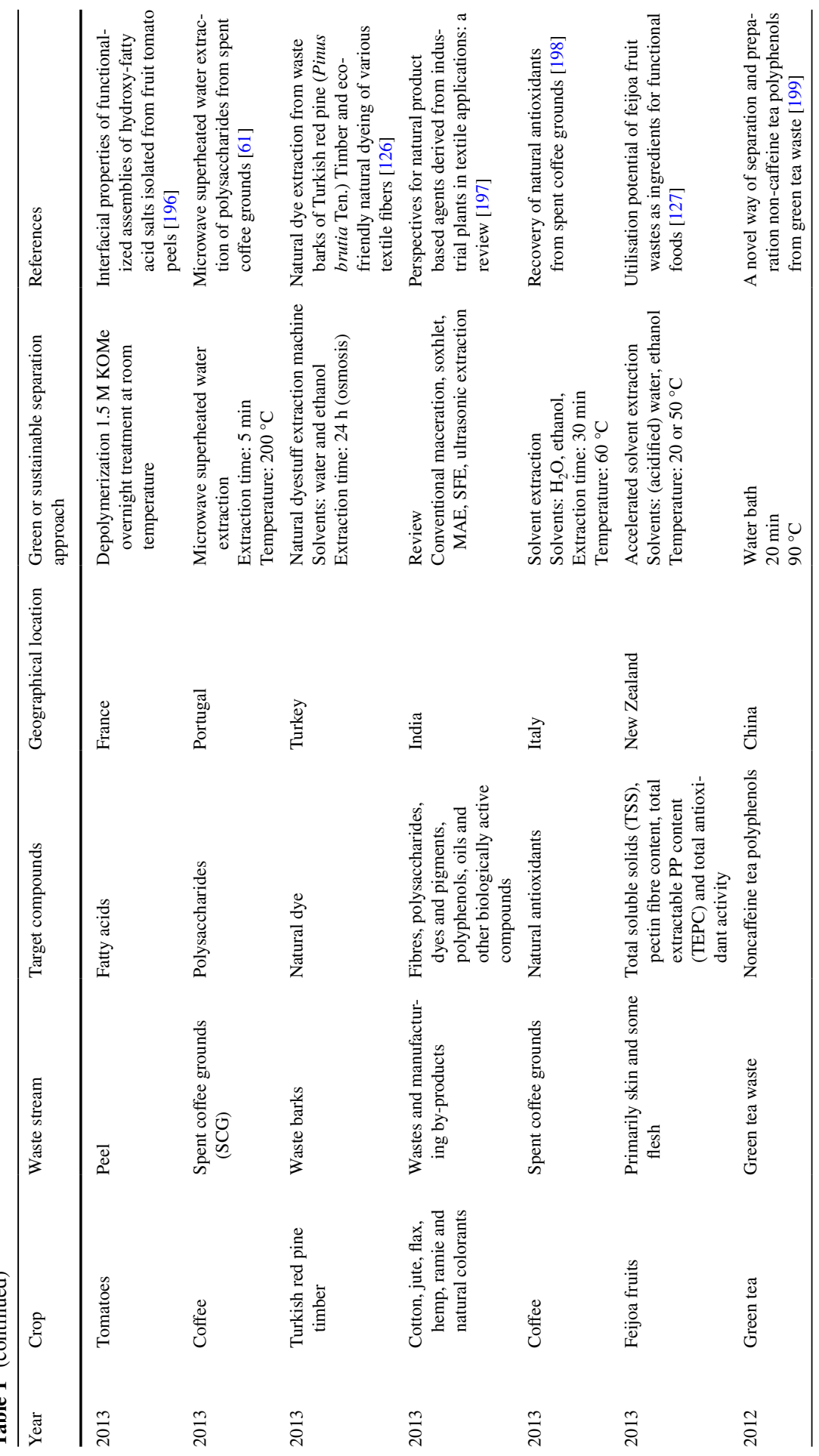




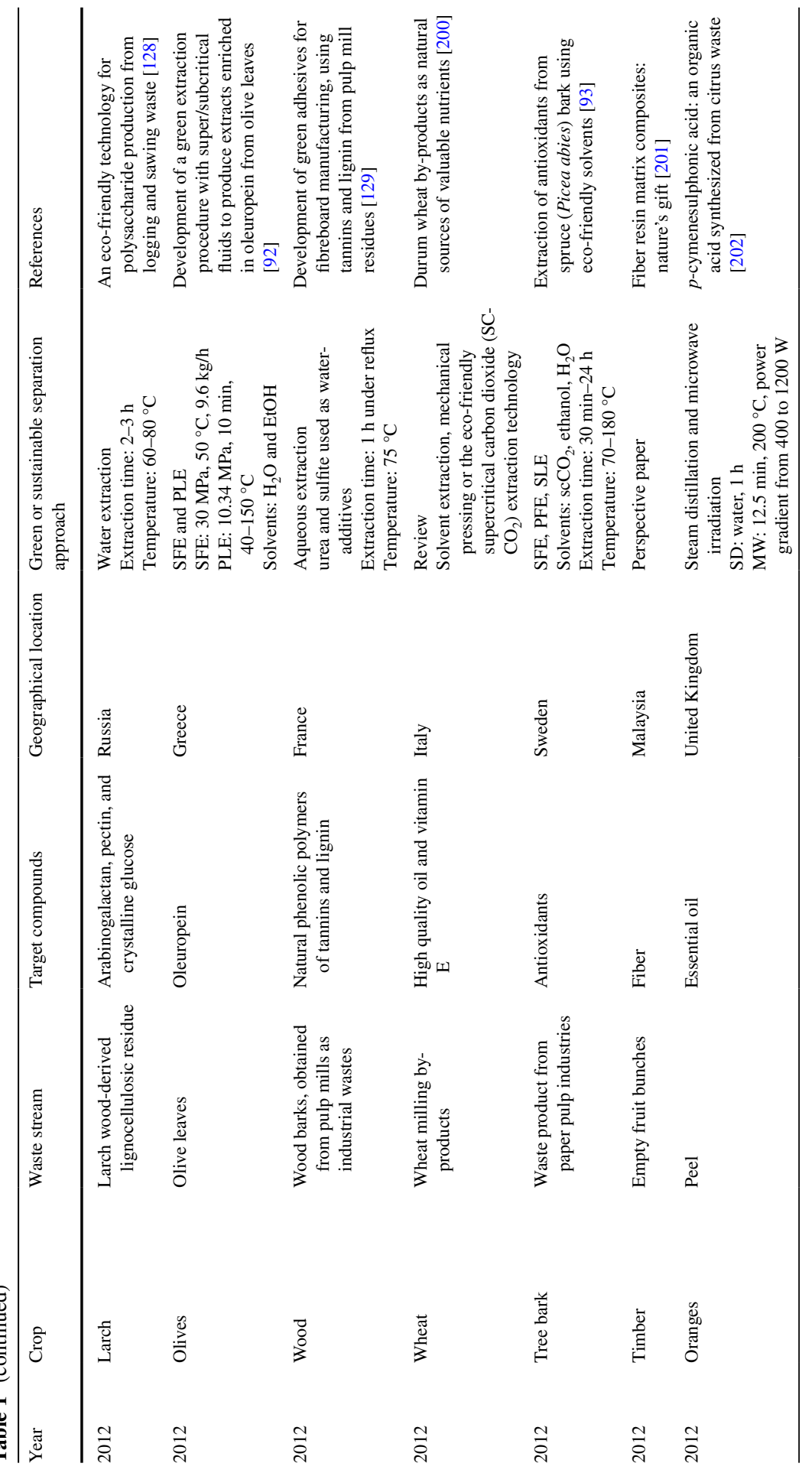




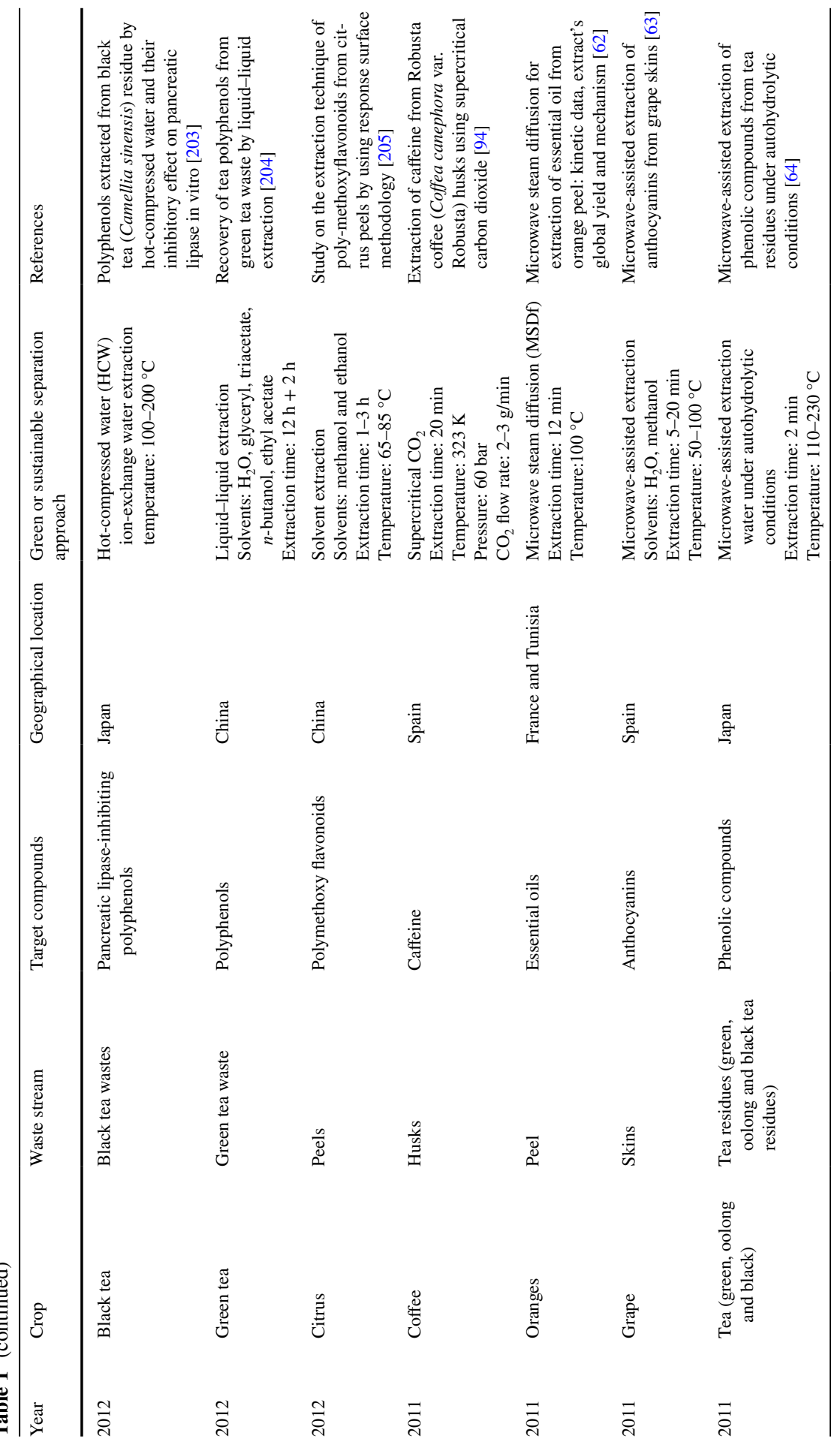




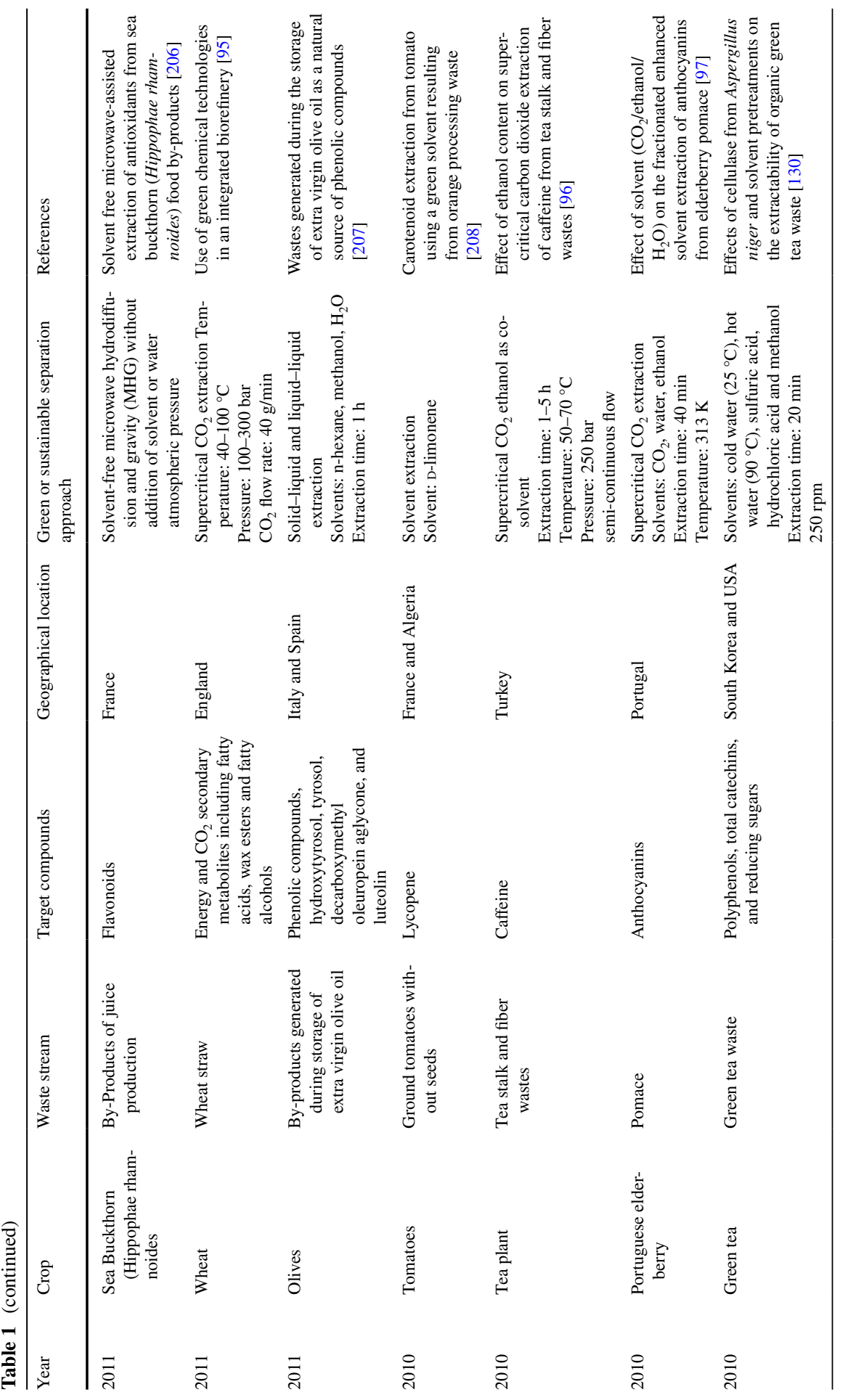




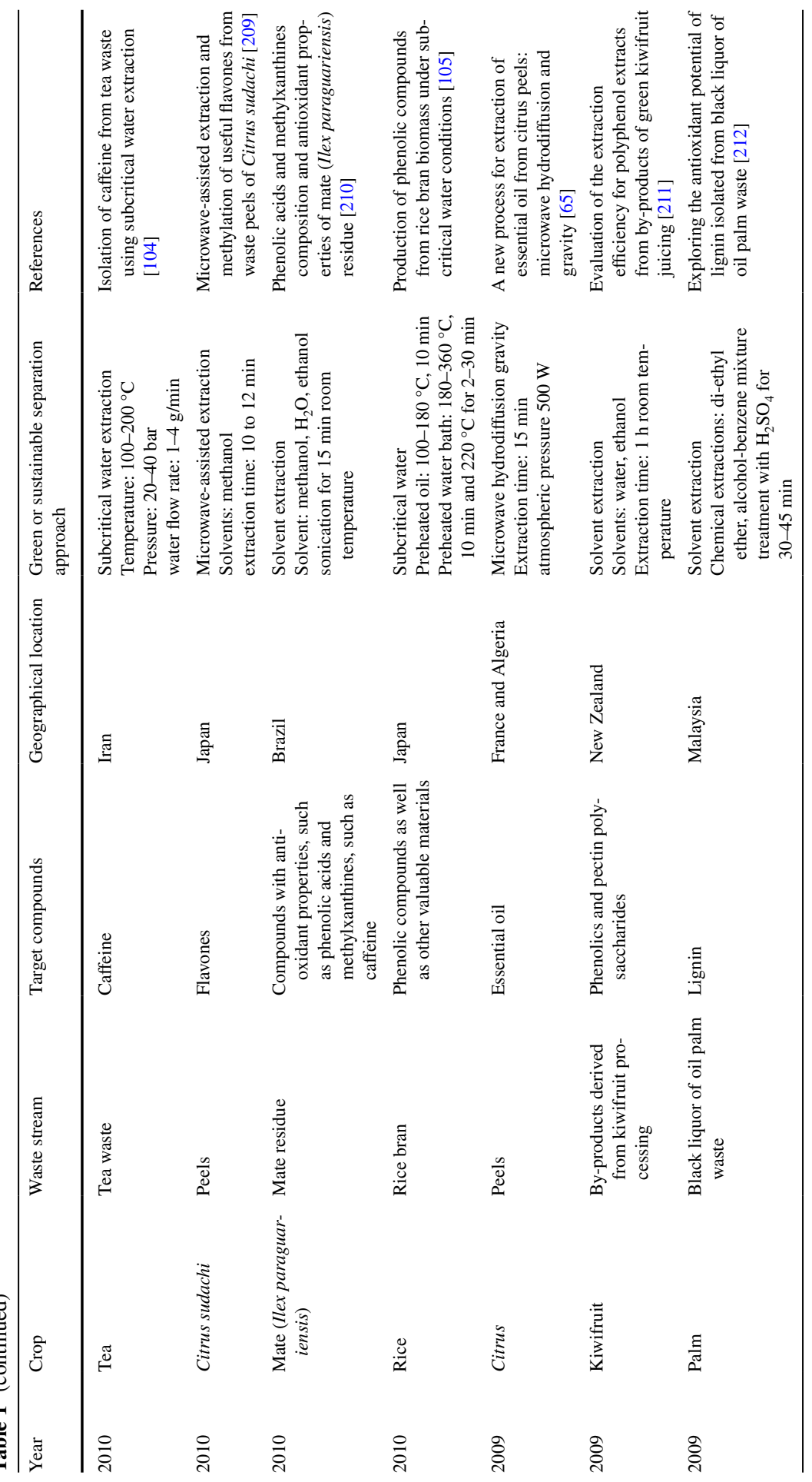




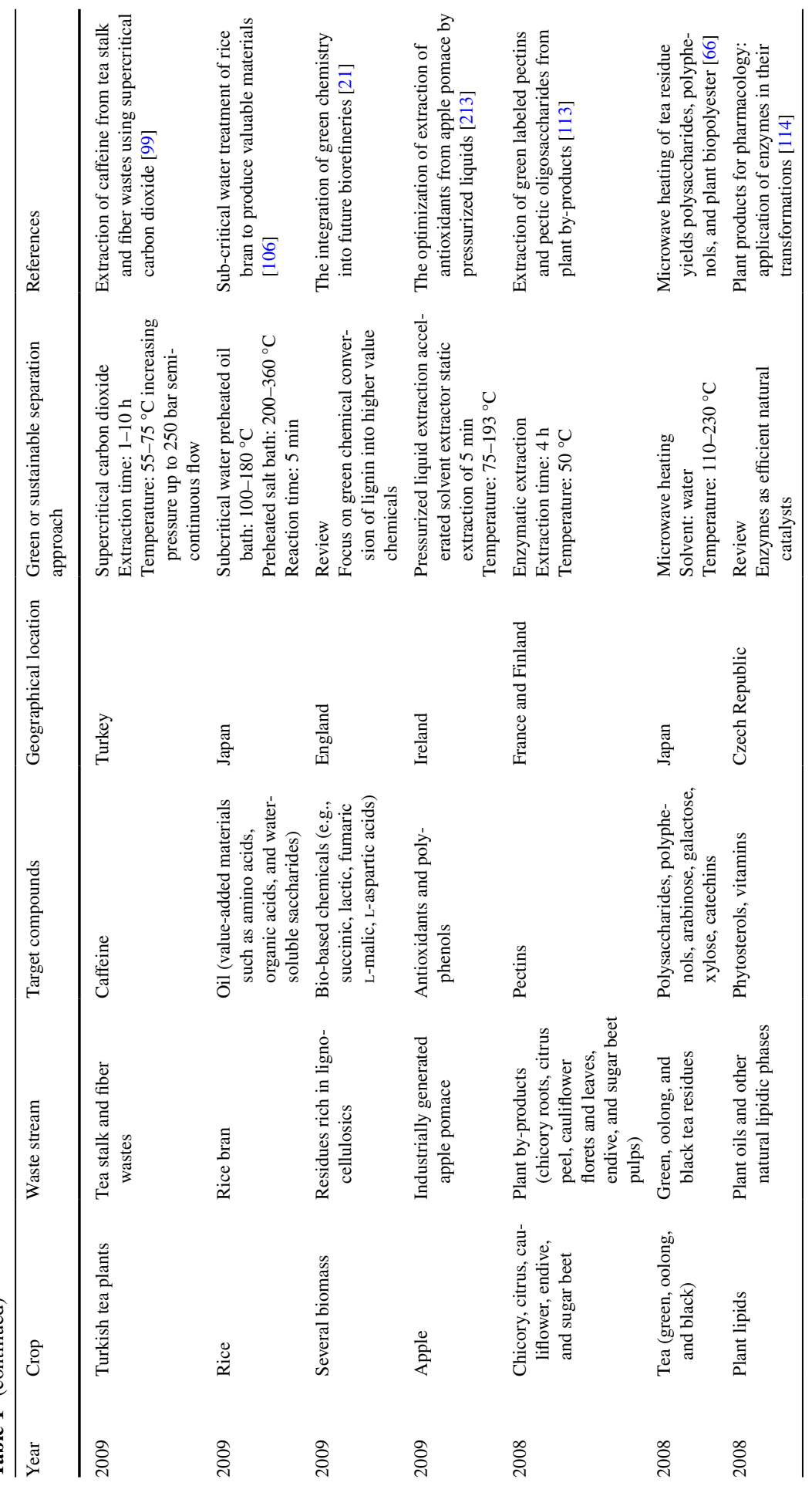




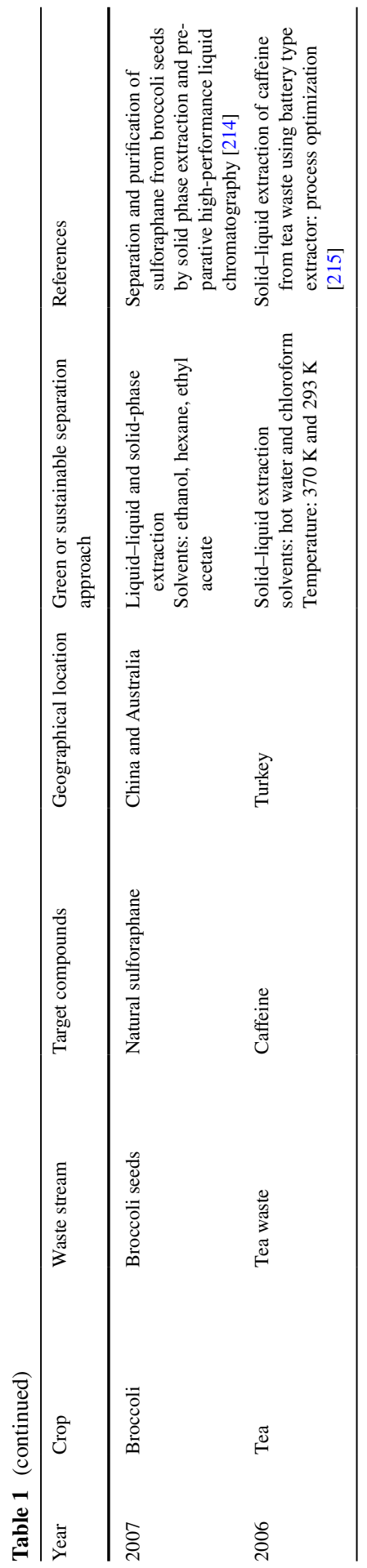


components in these matrices, such as water or high molecular weight compounds [39].

The decision concerning the best method to separate the compounds of interest from the raw material is dependent on several aspects, such as the characteristics of the target extracts and raw material (physical-chemical properties), available technology, required purity, selectivity, stability and, more importantly here, the greenness of the whole process. As can be seen in Fig. 5, the most cited techniques in these research papers were based on solvent/maceration $(25 \%$ of the total), microwave (19\%), ultrasonication (14.7\%) and supercritical fluid processing (13\%), followed by methods using ionic liquids $(7 \%)$, enzymatic and subcritical fluid treatment $(6 \%)$, as well as the association of two or more techniques.

According to the literature, the most widespread approaches for separating natural products from a number of matrices are based on liquid-liquid or solid-liquid extraction (LLE and SLE). Several greener alternatives have been proposed by replacing toxic or non-renewable organic solvents, as well as the extraction times. In some cases, solid-phase extractions (SPE) were also carried out and decreased both the amount of solvent and the number of extraction cycles, offering high enrichment factors [39, 40]. Actually, the mass transfer enhancement for SLE has been largely studied and applied, contributing to technology innovation, process intensification and integration, and energy saving, especially important for microwave, ultrasound, and high-pressure processing, for instance [41]. An overview of these techniques and related examples will be discussed in this section.

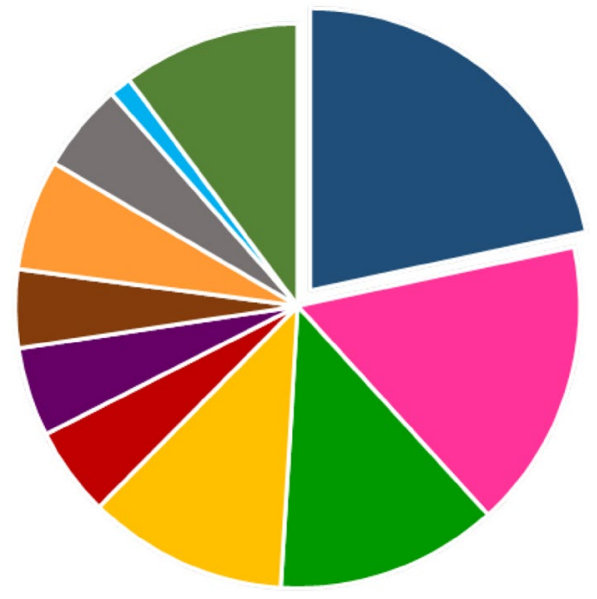

- Solvent processing

- Microwave processing

- Ultrasonication

- Supercritical fluid

- Enzymatic processing

- Alkaline processing

- Subcritical fluid

- Ionic Liquid

- Accelarated solvent

- Microemulsion

- Others

Fig. 5 Main green and sustainable techniques used to separate natural products from waste described in research papers (ISIS Web of Knowledge, January 2006 to December 2017) 


\subsection{From Conventional Solvent Separation to Enhancement Processing Approaches Over the Last 10 Years}

Solvent processing is one of the most traditional methods to remove natural products from bio-derived materials. In this extraction approach, the raw material in adequate size is exposed to different solvents, mostly organic, which remove soluble components of interest. The samples are then usually centrifuged and filtered to separate the solid residue, and the extract is used in this way (as a food supplement or for preparing functional foods, for example) or treated after this step. Solvent extraction is attractive compared to other methods due to low cost and simplicity. However, this method does not always use benign solvents; it frequently requires an evaporation/ concentration step for recovery, it usually demands large amounts of solvent and needs a long time to be carried out. Additionally, the possibility of thermal degradation of natural bioactive components is also possible due to the high temperatures used during the extraction process [42]. Despite this, it is largely used in industries, where solvent reuse is of great economic importance. In general, the raw material (in its liquid or solid form) is mixed with a solvent, and the separation kinetic of the target compounds is influenced by parameters such as the solvent ratio, $\mathrm{pH}$, and temperature and, for SLE, the particle size. The solvent should be atoxic, non-flammable and stable at working conditions, ideally renewable and cheap, with low viscosity and an adequate boiling point, allowing for easier solvent removal from the extract/ fraction [43]. Recently, several models have been proposed to predict the best solvents to be used in a specific case, which do not only take into account physical descriptors, such as enthalpy of vaporization, dielectric constant, refractive index, boiling point, etc., but also empirical descriptors to evaluate, for instance, intermolecular forces (specific and non-specific solute-solvent interactions, e.g., hydrogen bond donor and/or hydrogen bond acceptor, Van der Waals and ion/dipole forces). Purely theoretical descriptors have been also introduced, offering the most important advantage of not requiring any experiments, as is the case of the model known as quantitative structure property relationship (QSPR), able to predict 127 polarity scales for more than 700 solvents [44].

The solvent selection also depends on the physical-chemical proprieties of the compounds of interest, considering principally the selectivity and greenness degree of the process, aiming at obtaining high recoveries and the integrity of the target compounds. In general, the raw material stays in contact with the solvent for a certain period (from minutes to days), when the soluble compounds are transferred from the matrix to the extractor phase, usually by shaking the system. For SLE, the dispersion of the particles in the solvent is facilitated agitating them, optimizing their contact and accelerating the separation process. Traditionally, solvent treatment is performed at room temperature, although heating can promote higher recoveries to these compounds that are not thermosensitive. In some cases, LLE and SLE can be time-consuming, demanding further purification and concentration steps, which are their main drawbacks $[41,45]$.

Maceration using green and non-toxic solvents for the separation of natural products from plant-derived waste has been described over the last years (e.g., to remove dyes from quince leaves or catechins, theaflavins, gallic acid, and antioxidants in 
general from walnut green husk, cranberry pomace, black tea and banana processing waste). According to these studies, using water, methanol, ethanol or a mixture of them at $70-100{ }^{\circ} \mathrm{C}$ can be a low-cost, benign alternative for the recovery of high added-value compounds derived from residual biomass [46-49]. Scaling-up was also studied, whose results showed to be useful in determining industrial process feasibility and the economic value of polyphenols for commercial use, increasing the overall profitability of the cranberry industry [48].

Whenever possible, higher temperatures allow for higher mass transfer in a shorter time with lower energy consumption in general, resulting in better recovery efficiency than conventional systems [50]. As observed in Fig. 5, the second most cited green and sustainable separation process is based on microwave heating and can be considered a non-conventional technique nowadays. Heating is based on non-ionizing electromagnetic waves. Those between 0.915 and $2.45 \mathrm{GHz}$ are used for industrial, scientific and medical applications. The overall principle of heating is rooted in its direct impact with polar materials/solvents and is dependent on ionic conduction and dipole rotation, occurring simultaneously in most cases. The increased temperature can overcome the natural product-matrix interaction caused by Van der Waals forces, dipole attraction, hydrogen bonding of the compounds of interest and active sites in the matrix. Therefore, thermal energy can disrupt both solute-solute and solute-matrix interactions, providing the activation energy required for the desorption process. The mass transfer of the compounds from the raw material to the solvent is also accomplished by convection and diffusion mechanisms, causing the explosion of plant cells and releasing their content into the liquid phase [51].

The eco-friendly removal of essential oils, pectin and polyphenols from a number of plant raw materials mediated by microwave irradiation has been described over the last years, paying special attention to citrus waste [52-66]. In fact, the orange juice processing industry can be considered more than a good case study. This sector is highly wasteful, generating $50 \%$ of waste from the total fruit/starting material (e.g., peel, bagasse, seeds and yellow water). Around 20 million tonnes of orange peel per year are produced worldwide, which consist of water $(80 \%)$ and sugars, cellulose, hemicellulose, pectin and D-limonene (20\%). Recently, it was shown using a mathematical model that D-limonene extraction consisted of a two stage diffusion process for a microwave (MW) heating approach: initial extraction from the exterior of cells followed by trans-membrane diffusion. Compared to other conventional extraction methods, it was found that the microwave treatment was more efficient, resulting in a higher overall yield due to the access to a higher amount of D-limonene [59].

The successful microwave-assisted solvent-free modification of pectin derived from citrus waste has also been reported [53]. These approaches not only allow for the separation of the major components of citrus peel, but they also add further value through the production of other high value-added products, such as pectin, D-limonene and a rare form of mesoporous cellulose which are produced in a single step, without added acid [67]. Along these lines, the concept of dry-biorefinery is gaining momentum, since valuable products can be recovered from plant byproducts without adding solvents or water, using green processes such as MW [56]. 
Innovation relies on the separation of the target compounds from raw materials, which are rich in water, achieved without adding solvents or water, illustrating a circular systemic process; i.e., all materials and resources could be reintegrated into the integrated and zero-waste biorefinery [19]. Although very attractive, as expected, the design and use of real MW industrial scale equipment requires additional studies related to safety, corrosion and maintenance intervals [68].

The combination of two or more extraction/concentration methods is quite common in the literature (Table 1). As described by Boukroufa et al. [56], the removal of essential oil, polyphenols and pectin from orange waste was conducted using microwave and ultrasound technology, without adding any solvents. Essential oil separation was performed by Microwave Hydrodiffusion and Gravity (MHG), and thereafter the remaining water of this process was used as a solvent for the subsequent extraction of flavonoids and pectin. For polyphenol separation, ultrasound-assisted extraction (UAE) was used, and response surface methodology (RSM) using the central composite design (CCD) approach was used to investigate the influence of some variables. The CCD revealed that the optimized conditions of ultrasound power and temperature were $0.956 \mathrm{~W} / \mathrm{cm}^{2}$ and $59.83{ }^{\circ} \mathrm{C}$ giving a polyphenol yield of $50.02 \mathrm{mg} \mathrm{GA} / 100 \mathrm{~g} \mathrm{dm}$, which, compared to conventional extraction, promoted an increase of $30 \%$ in the yield. Pectin was extracted by microwave-assisted extraction, resulting in a maximal yield of $24.2 \%$ for microwave power of $500 \mathrm{~W}$ ( $3 \mathrm{~min}$ ), whereas traditional extraction provides $18.32 \%$ (120 min). As can be seen, the combination of microwave, ultrasound and recycled water resulted in higher recoveries of the compounds of interest in a shorter time, so that a systemic loop/cycle could be closed using only the resources generated in the plant. This makes the whole process optimized in terms of time, energy savings, cleanliness and reduced amount of waste.

As can be noted, ultrasound has been widely utilized for helping to extract target components from waste plant-derived sources, reducing separation time, solvents, energy consumption and improving the product quality. The effectiveness of ultrasound is attributed to the cavitation phenomenon, assisting the solubilization of the compounds of interest into the solvent, enhancing their removal from the bulk raw material [69]. According to Chemat [70], the ultrasound waves (from $20 \mathrm{kHz}$ to $10 \mathrm{MHz}$ ) pass through an elastic medium, inducing a longitudinal displacement of particles resulting in a succession of compression and rarefaction phases in this medium. Every medium has a critical molecular distance and, below this critical point, the liquid remains intact. However, above this distance, the liquid would break down, creating voids (cavitation bubbles) in the liquid. When the size of these bubbles reaches a critical point they collapse, releasing a large amount of energy. The estimated temperature and pressure at this time are estimated at 5000 and $2000 \mathrm{~K}$ atmospheres. This creates hotspots that accelerate the chemical reactivity into the medium, generating microjets directed towards the solid surface, also responsible for the general higher effectiveness of this technique, as the high pressure and temperature involved in the process destroy the cell walls of the plant matrices and their content can be released into the medium more easily.

Some new process aiming at agro-industrial waste application in food industries based on ultrasound-assisted extraction of natural products have been reported 
[71-79], as is the case of carotenoid separation from pomegranate peels using different vegetable oils as solvents [72]. Sunflower and soybean oils were used as solvents and parameters such as time, temperature, solid/oil ratio used were analyzed considering the yield. It was found that the optimum mild operating conditions were: extraction temperature, $51.5{ }^{\circ} \mathrm{C}$; peel/solvent ratio, 0.10; amplitude level, 58.8\%; solvent, sunflower oil. Additionally, a subsequent separation of oil and carotenoids was not necessary, since the pigmented oil can be used as a carotenoid source in different commercial products in this format.

The green recovery of cellulose from oil palm bunches by autoclave-based and ultrasonication pre-treatments were successfully developed to replace the non-green chlorite method [73]. An ultrasonic process with hydrogen peroxide yielded 49\% cellulose with $9.13 \%$ alpha-cellulose content and $68.7 \%$ crystallinity, as compared to $64 \%$ cellulose with an autoclave treatment. The cellulose/polypropylene composites generated with high tensile strength, high thermal stability, and low water and diesel sorption showed great potentials for conversion into eco-composite products such as polymeric material insulated cables for high voltage engineering, automotive parts, sports tools and other household or office items.

Another highly cited green and sustainable technique to isolate organic compounds from bio-based waste is based on supercritical fluid processing (Fig. 5). It is widely known that substances at temperatures and pressures near or above their critical points have exceptional solvent characteristics for analytical purposes. These supercritical fluids possess liquid-like solvating and gas-like diffusivity power, and other tuneable properties that can be adjusted varying temperature, pressure and the addition of other components acting as a modifier. Due to its gas-like low viscosity and high diffusivity, the supercritical fluid can easily penetrate into plant materials with a fast mass transfer rate. Possibly, the most important property of supercritical fluids for separation processes is diffusion, obtaining solubility and diffusion good enough to provide quantitative extraction yield [80, 81]. Carbon dioxide $\left(\mathrm{scCO}_{2}\right)$ is the fluid most widely used for extractions, with critical parameters of $31.1^{\circ} \mathrm{C}$ and $73 \mathrm{~atm}(7.39 \mathrm{MPa})$, at relatively low operating conditions. It behaves as a nonpolar or polarizable solvent and low molar mass alcohols (co-solvents) are often added in small quantities to modify the solvent polarity. Because carbon dioxide can be depressurized to the gaseous state, the solvent is easily removed and supercritical fluid-based separation methods are easily coupled with subsequent analysis. Therefore, $\mathrm{scCO}_{2}$ provides miscibility to the majority of natural products, availability and low cost, reliably high purity, negligible toxicity, facility for removal and reuse, resulting in many advantages for downstream processing in terms of product purification and/or catalyst recycling [80].

The approach using $\mathrm{scCO}_{2}$ has been widely used for isolation and purification of chlorophylls, carotenoids, lipids, alkaloids, antioxidants from matrices such as filter tea, spruce bark, tomato and elderberry pomace, grape, passiflora, coffee and cupuassu seed waste [82-99]. In addition to the optimization of the separation process, some studies also aim to evaluate the techno-economic viability of large-scale commercial production, for example, to obtain cupuassu butter from cold-pressed seed residues, also evaluating the influence of thermodynamic and kinetic variables of yield, chemical composition and production costs of the extracts [86]. Optimal 
conditions related to extraction kinetics, chemical composition and production costs were $30-35 \mathrm{MPa}$ and $50{ }^{\circ} \mathrm{C}$. It was shown that the phenolic content $(0.47-2.82 \mathrm{mg} / \mathrm{g})$ was lower than those commonly found using other methods $(20-23 \mathrm{mg} / \mathrm{g})$. The high contents of tocopherols, as well as the unsaturated fatty acids (48\%) compared to the saturated fatty acids (52\%) present in the butter obtained by $\mathrm{scCO}_{2}$ demonstrated its great potential as an ingredient in food, pharmaceutical and cosmetic industries. In addition, process intensification for biodiesel production involving supercritical fluids has been reported [84, 90]. Such approaches can allow biodiesel production without any addition of catalyst, or via catalytic in situ or reactive extraction process, combining the extraction and reaction phase together in a single operation unit. These studies also discuss both processes towards the future bio-refinery setup and more efficient use of all waste produced.

The use of fluids different to $\mathrm{CO}_{2}$ has been described in the literature, but as they are usually organic solvents, they do not show any distinct advantages and often have high critical temperatures. Despite having a very high critical temperature, water shows unique properties in the subcritical region $\left(200-300{ }^{\circ} \mathrm{C}\right)$, as a reduction in dielectric constant (20-30) and density $\left(0.7-0.8 \mathrm{~g} / \mathrm{cm}^{3}\right)$ compared to water at room temperature, improving its ability to dissolve nonpolar organic and inorganic compounds. Under these conditions, the water dissociation constant into hydroxide and hydrogen ions are more than three orders of magnitude higher, so that nearcritical water acts as a self-neutralizing acid or base catalyst, avoiding salt waste generation. Moreover, using subcritical and supercritical water conditions greatly simplifies the product purification step in some cases, since nonpolar products are insoluble in water in lower temperatures [80, 100-106].

Other potential scalable approaches have been described, such as enzymatic [107-114], alkaline [115-120] and based on different types of aqueous media (e.g., cyclodextrins, montmorillonite $\mathrm{K}-10 / \mathrm{LiOH}$, green liquor) [121-130]; ionic liquids [131-135], deep eutectic solvents [136-138], constituting alternative methods for the recovery of high added-value compounds from agro-industrial waste aiming at obtaining the best analytical, economical and socio-environmental compromise [139-142].

Based on the investigated literature [143], Table 2 summarizes the advantages and disadvantages of the four most cited green and sustainable techniques.

\section{Conclusions}

The establishment of vanguard biorefineries for bioeconomy and circular economy urgently demands innovation in green and sustainable separation for the recovery of natural products from agro-industrial by-products all over the world. Sustainable separation includes the idea of integrated valorization not only in an economic sense, but also strengthens other social and environmental dimensions, from small to large producing scales. According to the literature over the last decade, the number of studies in this field has grown significantly in recent years. New approaches incorporating holistic extraction and/or purification techniques, also integrating systemic chemical transformation through the design and use of renewable materials 


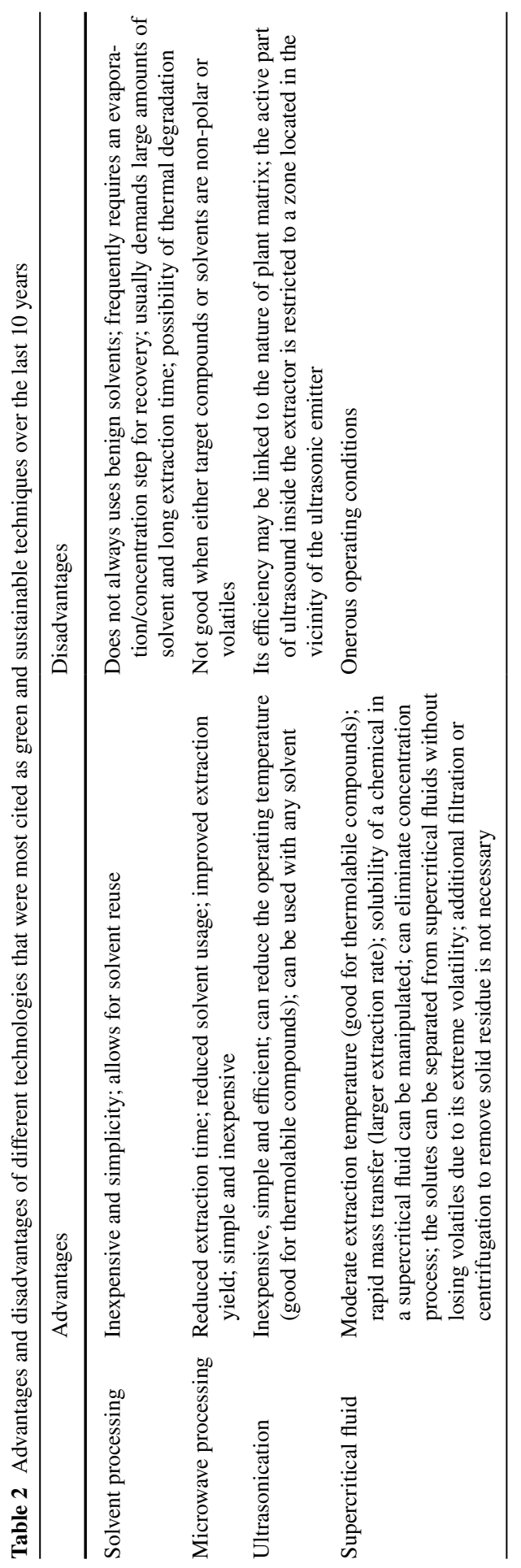


and optimized processes should combine the best green analytical figures of merit with online evaluation of the whole production chain. These approaches should generate healthier and more efficient products, methods and processes at an affordable and fair cost.

Overall, solvent processing and its modification towards the enhancement of mass transfer to remove the compounds of interest from selected waste have been widely used (25\%), also on industrial scales. Alternative extraction or purification methods have shown increasingly more applications, such as for microwave, ultrasonication and supercritical fluid processing. It was shown that a wide range of natural products and their derivatives are used mainly in food (as dyes, aromas, flavors) in medicines or green formulations in agriculture. According to the data available, one paradigmatic case largely studied is the valorization of citrus waste, representing more than $10 \%$ of all residues considered in the research papers.

Moreover, an emergent challenging topic is to evaluate biorefinery processing alternatives, i.e., sustainability assessment tools, for example LCA, which include parameters such as feedstock supply (to verify the suitability and adequacy of a potential biomass feedstock for the separation or transformation treatment), process performance (to assess the input-output balance of material and energy flows) and bio-based chemical production [144]. Therefore, the decision about the best separation approach takes into account various fundamental aspects and is based on green and sustainable assessment tools, considering the type of agro-industrial waste (e.g., quantity, periodicity, chemical variability, water amount, distance to the processing unit), the natural target products (chemical quality, purity, humidity, costs etc.) and available technologies.

Using sustainability indicators and tools will be increasingly demanded in this field, contributing to the greenness or sustainability of the whole processing system. The development of a sustainable separation method which provides better recovery efficiency will not only add value to the agro-industrial waste, reducing the overall manufacturing costs and the use of synthetic chemicals, but will also aggregate value to the whole production chain, including its final products. The emergence of bio-based industries is changing the current status of the producing systems, contributing to the current biomass residual losses. Based on the literature, the scenario for future research and innovation in green and sustainable separation for the recovery of agro-industrial waste is truly beginning, bringing together various areas and sectors towards more efficient and circular systems.

Acknowledgements The authors wish to thank FAPESP (13/12052-5, 14/50827-1), Capes (2032/201407), EPSRC-UK (EP/M028763/1) and Mateus Segatto.

Open Access This article is distributed under the terms of the Creative Commons Attribution 4.0 International License (http://creativecommons.org/licenses/by/4.0/), which permits unrestricted use, distribution, and reproduction in any medium, provided you give appropriate credit to the original author(s) and the source, provide a link to the Creative Commons license, and indicate if changes were made. 


\section{References}

1. Liu J, Mooney H, Hull V, Davis SJ, Gaskell J, Hertel T, Lubchenco J, Seto KC, Gleick P, Kremen C, Li S (2015) Systems integration for global sustainability. Science 347:12588320-12588329

2. Kiser B (2016) Circular economy: getting the circulation going. Nature 53:443-446

3. Food and Agriculture Organization of the United Nations. World hunger on the rise again, reversing years of progress. http://www.fao.org/news/story/en/item/902489/icode/. Accessed 03 Jul 2017

4. Godfray HCJ, Beddington JR, Crute IR, Haddad L, Lawrence D, Muir JF, Pretty J, Robinson S, Thomas SM, Toulmin C (2010) Food security: the challenge of feeding 9 billion people. Science 327(5967):812-818

5. United Nations (2015) World Population prospects: the 2015 revision and key findings and advance tables. United Nations, New York. https://esa.un.org/unpd/wpp/publications/files/key_findings _wpp_2015.pdf. Accessed 20 Oct 2016

6. Xia H, Houghton JA, Clark JH, Matharu AS (2016) Potential utilization of unavoidable food supply chain wastes-valorization of pea vine wastes. ACS Sustain Chem Eng 4(11):6002-6009

7. Aschemann-Witzel J (2016) Waste not, want not, emit less. Science 2978(6284):408-409

8. Perlatti B, Forim MR, Zuin VG (2014) Green chemistry, sustainable agriculture and processing systems: a Brazilian overview. Chem Biol Technol Agric 1:5-9

9. Foster-Carneiro L, Berni MD, Dorileo IL, Rostagno MA (2013) Biorefinery study of availability of agriculture residues and wastes for integrated biorefineries in Brazil. Resour Conserv Recycl 77:78-88

10. Tuck CO, Perez E, Horvath IT, Sheldon RA, Poliakoff M (2012) Valorization of biomass: deriving more value from waste. Science 337:695-699

11. Lin CSK, Pfaltzgraff LA, Herrero-Davila L, Mubofu EB, Abderrahim S, Clark JH, Koutinas AA, Kopsahelis N, Stamatelatou K, Dickson F, Thankappan S, Mohamed Z, Brocklesby R, Luque R (2013) Food waste as a valuable resource for the production of chemicals, materials and fuels. Current situation and global perspective. Energy Environ Sci 6(2):426-464

12. Lin CSK, Koutinas AA, Stamatelatou K, Mubofu EB, Matharu AS, Kopsahelis N, Pfaltzgraff LA, Clark JH, Papanikolaou S, Kwan TH, Luque R (2014) Current and future trends in food waste valorization for the production of chemicals, materials and fuels: a global perspective. Bioprod Biorefin Biofuels 8(5):686-715

13. Lin CSK, Luque R (2014) Renewable resources and biorefineries. Royal Society of Chemistry, Cambridge

14. Papargyropoulou E, Lozano R, Steinberger J, Wright N, Zb Ujang (2014) The food waste hierarchy as a framework for the management of food surplus and food waste. J Clean Prod 76:106-115

15. European Parliament Council. Directive 2008/1/EC of the European Parliament and of the council of 15 January 2008 concerning integrated pollution prevention and control

16. Ragauskas AJ, Williams CK, Davison BH, Britovsek G, Cairney J, Eckert CA, Frederick WJ, Hallett JP, Leak DJ, Liotta CL, Mielenz JR, Murphy R, Templer R, Tschaplinski T (2006) The path forward for biofuels and biomaterials. Science 311:484-489

17. Mohan SV, Nikhil GN, Chiranjeevi P, Reddy CN, Rohit MV, Kumar AN, Sarkar O (2016) Waste biorefinery models towards sustainable circular bioeconomy: critical review and future perspectives. Bioresour Technol 215:2-12

18. Clark JH, Deswarte F (2015) Introduction to chemicals from biomass, 2nd edn. John Wiley and Sons Ltd., Chichester

19. Zuin VG (2016) Circularity in green chemical products, processes and services: innovative routes based on integrated eco-design and solution systems. Curr Opin Green Sustain Chem 2:40-44

20. Anastas PT (1999) Green chemistry and the role of analytical methodology development. Crit Rev Anal Chem 29:167-175

21. Clark JH, Deswarte FEI, Farmer TJ (2009) The integration of green chemistry into future biorefineries. Biofuels Bioprod Biorefin 3:72-90

22. Chemat F, Avian M, Cravotto G (2012) Green extraction of natural products: concept and principles. Int J Mol Sci 13:8615-8627

23. Clark JH, Budarin V, Deswarte FEI, Hardy JJE, Kerton FM, Hunt AJ, Luque R, Macquarrie DJ, Milkowski K, Rodriguez A, Samuel O, Tavener SJ, White RJ, Wilson AJ (2006) Green chemistry and the biorefinery: a partnership for a sustainable future. Green Chem 8:853-860 
24. Sustainable Chemistry (2017) The Organisation for Economic Co-operation and Development (OECD). Paris. http://www.oecd.org/chemicalsafety/risk-management/sustainablechemistry.htm Accessed 07 Jul 2017

25. Sustainable chemistry (2017) Umweltbundesamt, Dessau-Roßlau Germany. http://www.umwe ltbundesamt.de/en/topics/chemicals/chemicals-management/sustainable-chemistry\#textpart-1. Accessed 07 Jul 2017

26. Campbell SD (2016) The planner's triangle revisited: sustainability And the evolution of a planning ideal that can't stand still. JAPA 82(4):388-397

27. Hanson JR (2003) Natural products: the secondary metabolites. RSC, Cambridge

28. Armenta S, Garrigues S, de la Guardia M (2015) The role of green extraction techniques in Green Analytical Chemistry. TrAC Trends Anal Chem 71:2-8

29. Zuin VG (2016) Green sample preparation of complex matrices: towards sustainable separations of organic compounds based on the biorefinery concept. Pure Appl Chem 88:29-36

30. Zuin VG, Budarin VL, De Bruyn M, Shuttleworth PS, Hunt AJ, Pluciennik C, Borisova A, Dodson JR, Parker H, Clark J (2017) Polysaccharide-derived mesoporous materials (Starbon ${ }^{\circledR}$ ) for sustainable separation of complex mixtures. Faraday Discuss 196:1-9

31. Jessop PG (2016) The use of auxiliary substances (e.g. solvents, separation agents) should be made unnecessary wherever possible and innocuous when used. Green Chem 18:2577-2578

32. Kiss AA, Lange J-P, Schuur B, Brilman DWF, van der Ham AGJ, Kersten SRA (2016) Separation technology: making a difference in biorefineries. Biomass Bioenergy 95:296-309

33. Long Z, Budarin V, Jiajun F, Sloan R, MacQuarrie DJ (2017) Efficient method of lignin isolation using microwave-assisted acidolysis and characterisation of the residual lignin. ACS Sustain Chem Eng 5:3768-3774

34. Abou-Shehada S, Clark JH, Paggola G, Sherwood J (2016) Tunable solvents: shades of green. Chem Eng Process 99:88-96

35. Lachos-Perez D, Brown AB, Mudhoo A, Martinez J, Timko MT, Rostagno MA, Forster-Carneiro $\mathrm{T}$ (2017) Applications of subcritical and supercritical water conditions for extraction, hydrolysis, gasification, and carbonization of biomass: a critical review. Biofuels 14:611-626

36. Filly A, Fabiano-Tixier AS, Louis C, Fernandez X, Chemat F (2016) Water as a green solvent combined with different techniques for extraction of essential oil from lavender flowers. C R Chim 19:707-717

37. Chemat F, Strube J (2015) Green extraction of natural products. Wiley, Weinheim

38. Costa ES, Perlatti B, Silva EM, Matos AP, Silva MFGF, Fernandes JB, Zuin VG, Silva CMP, Forim MR (2017) Use of lignins from sugarcane bagasse for assembling microparticles loaded with Azadirachta indica extracts for use as neem-based organic insecticides. J Braz Chem Soc 28:126-135

39. Guardia M, Garrides S (2012) Handbook of green analytical chemistry. Wiley, New York

40. Braga EM, Seabra IJ, Dias AMA, Sousa HC (2013) Recent trends and perspectives for the extraction of natural products. In: Rostagno M, Prado J (eds) Natural product extraction. RSC, Cambridge

41. Both S, Strube J, Cravatto G (2015) Mass transfer enhancement for solid-liquid extractions. In: Chemat F, Strube J (eds) Green extraction of natural products: theory and practice. Wiley, Weinheim

42. Kumar K, Yadav AN, Kumar V, Vyas P, Dhaliwal HS (2017) Food waste: a potential bioresource for extraction of nutraceuticals and bioactive compounds. Bioresour Bioprocess 4(1):18

43. Regulation (EC) No 1907/2006 (2006) European Parliament and of the council concerning the registration, evaluation, authorisation and restriction of chemicals (REACH), European Commission, Luxembourg. http://eur-lex.europa.eu/legal-content/EN/TXT/?uri=CELEX\%3A02006R1907-2014 0410 Accessed 21 Jul 2017

44. Chemat F, Vian MA (2014) Alternative solvents for natural products extraction. Springer, Heidelberg

45. Ibanez E, Cifuentes A (2017) Green extraction techniques: principles, advances and applications. Elsevier, Amsterdam

46. Güçlü Üstündağ Ö, Erşan S, Özcan E, Özan G, Kayra N, Ekinci FY (2016) Black tea processing waste as a source of antioxidant and antimicrobial phenolic compounds. Eur Food Res Technol 242:1523-1532

47. Toh PY, Leong FS, Chang SK, Khoo HE, Yim HS (2016) Optimization of extraction parameters on the antioxidant properties of banana waste. Acta Sci Pol Technol Aliment 15:65-78 
48. Harrison JE, Oomah BD, Diarra MS, Ibarra-Alvarado C (2013) Bioactivities of pilot-scale extracted cranberry juice and pomace. J Food Process Preserv 37:356-365

49. Fernández-Agulló A, Pereira E, Freire MS, Valentao P, Andrade PB, González-Álvarez J, Pereira JA (2013) Influence of solvent on the antioxidant and antimicrobial properties of walnut (Juglans regia L.) green husk extracts. Ind Crops Prod 42:126-132

50. Bravo J, Monente C, Juániz I, De Peña MP, Cid C (2013) Influence of extraction process on antioxidant capacity of spent coffee. Food Res Int 50:610-616

51. Clodoveo ML, Dipalmo T, Rizzello CG, Corbo F, Crupi P (2016) Emerging technology to develop novel red winemaking practices: an overview. Innov Food Sci Emerg Technol 38:41-56

52. Liu Z, Zu Y, Yang L (2017) A process to preserve valuable compounds and acquire essential oils from pomelo flavedo using a microwave irradiation treatment. Food Chem 224:172-180

53. Fidalgo A, Ciriminna R, Carnaroglio D, Tamburino A, Cravotto G, Grillo G, Ilharco L, Pagliaro M (2016) Eco-friendly extraction of pectin and essential oils from orange and lemon peels. ACS Sustain Chem Eng 4:2243-2251

54. Zainab H, Nurfatirah N, Norfaezah A, Othman H (2016) Green bio-oil extraction for oil crops. IOP Conf Ser Mater Sci Eng 133:12053

55. González-Rivera J, Spepi A, Ferrari C, Duce C, Longo I, Falconieri D, Piras A, Tinè MR (2016) Novel configurations for a citrus waste based biorefinery: from solventless to simultaneous ultrasound and microwave-assisted extraction. Green Chem 18:6482-6492

56. Jacotet-Navarro M, Rombaut N, Deslis S, Fabiano-Tixier AS, Pierre FX, Bily A, Chemat F (2016) Towards a "dry" bio-refinery without solvents or added water using microwaves and ultrasound for total valorization of fruit and vegetable by-products. Green Chem 18:3106-3115

57. Boukroufa M, Boutekedjiret C, Petigny L, Rakotomanomana N, Chemat F (2015) Bio-refinery of orange peels waste: a new concept based on integrated green and solvent free extraction processes using ultrasound and microwave techniques to obtain essential oil, polyphenols and pectin. Ultrason Sonochem 24:72-79

58. Alexandru L, Binello A, Mantegna S, Boffa L, Chemat F, Cravotto G (2014) Efficient green extraction of polyphenols from post-harvested agro-industry vegetal sources in Piedmont. C R Chim 17:212-217

59. Attard TM, Watterson B, Budarin VL, Clark JH, Hunt AJ (2014) Microwave-assisted extraction as an important technology for valorising orange waste. N J Chem 38:2278-2283

60. Ahangari B, Sargolzaei J (2013) Extraction of lipids from spent coffee grounds using organic solvents and supercritical carbon dioxide. J Food Process Preserv 37:1014-1021

61. Passos CP, Coimbra MA (2013) Microwave superheated water extraction of polysaccharides from spent coffee grounds. Carbohydr Polym 94:626-633

62. Farhat A, Fabiano-Tixier A-S, El Maataoui M, Maingonnat JF, Romdhane M, Chemat F (2011) Microwave steam diffusion for extraction of essential oil from orange peel: kinetic data, extract's global yield and mechanism. Food Chem 125:255-261

63. Liazid A, Guerrero RF, Cantos E, Palma M, Barroso CG (2011) Microwave-assisted extraction of anthocyanins from grape skins. Food Chem 124:1238-1243

64. Tsubaki S, Sakamoto M, Azuma J (2010) Microwave-assisted extraction of phenolic compounds from tea residues under autohydrolytic conditions. Food Chem 123:1255-1258

65. Bousbia N, Vian MA, Ferhat MA, Meklati BY, Chemat F (2009) A new process for extraction of essential oil from Citrus peels: microwave hydrodiffusion and gravity. J Food Eng 90:409-413

66. Tsubaki S, Iida H, Sakamoto M, Azuma J (2008) Microwave heating of tea residue yields polysaccharides, polyphenols, and plant biopolyester. J Agric Food Chem 56:11293-11299

67. Balu AM, Budarin V, Shuttleworth PS, Pfaltzgraff LA, Waldron K, Luque R, Clark JH (2012) Valorisation of orange peel residues: waste to biochemicals and nanoporous materials. Chemsuschem 5:1694-1697

68. Chemat F, Cravotto G (2013) Microwave-assisted extraction for bioactive compounds: theory and practice. Springer, Heidelberg

69. Preece KE, Hooshyar N, Krijgsman AJ, Fryer PJ, Zuidam NJ (2017) Pilot-scale ultrasound-assisted extraction of protein from soybean processing materials. J Food Eng 206:1-12

70. Chemat F, Huma Z, Khan MK (2011) Applications of ultrasound in food technology: processing, preservation and extraction. Ultrason Sonochem 18:813-835

71. Bibi I, Sultan A, Kamal S, Nouren S, Safa Y, Jalani K, Sultan M, Atta S, Rehman F (2017) Extraction and quantification of phenolic compounds from Prunus armeniaca seed and their role in biotransformation of xenobiotic compounds. Korean J Chem Eng 34(2):392-399 
72. Goula AM, Ververi M, Adamopoulou A, Kaderides K (2017) Green ultrasound-assisted extraction of carotenoids from pomegranate wastes using vegetable oils. Ultrason Sonochem 34:821-830

73. Abdullah MA, Nazir MS, Raza MR, Wahjoedi BA, Yussof AW (2016) Autoclave and ultra-sonication treatments of oil palm empty fruit bunch fibers for cellulose extraction and its polypropylene composite properties. J Clean Prod 126:686-697

74. Trasanidou D, Apostolakis A, Makris DP (2016) Development of a green process for the preparation of antioxidant and pigment-enriched extracts from winery solid wastes using response surface methodology and kinetics. Chem Eng Commun 203:1317-1325

75. Mouratoglou E, Malliou V, Makris DP (2016) Novel glycerol-based natural eutectic mixtures and their efficiency in the ultrasound-assisted extraction of antioxidant polyphenols from agri-food waste biomass. Waste Biomass Valoriz 7:1377-1387

76. Paleologou I, Vasiliou A, Grigorakis S, Makris DP (2016) Optimisation of a green ultrasoundassisted extraction process for potato peel (Solanum tuberosum) polyphenols using bio-solvents and response surface methodology. Biomass Convers Biorefin 6:289-299

77. Li A-N, Li S, Xu D-P, Xu X-R, Chen Y-M, Ling W-H, Chen F, Li H-B (2015) Optimization of ultrasound-assisted extraction of lycopene from papaya processing waste by response surface methodology. Food Anal Methods 8:1207-1214

78. Geerkens CH, Matejka AE, Carle R, Schweiggert RM (2015) Development and validation of an HPLC method for the determination of alk(en)ylresorcinols using rapid ultrasound-assisted extraction of mango peels and rye grains. Food Chem 169:261-269

79. Punzi R, Paradiso A, Fasciano C, Trani A, Faccia M, de Pinto MC, Gambacorta G (2014) Phenols and antioxidant activity in vitro and in vivo of aqueous extracts obtained by ultrasound-assisted extraction from artichoke by-products. Nat Prod Commun 9:1315-1318

80. Guardia M, Garrides S (2011) Challenges in green analytical chemistry. RSC, Cambridge

81. Khaw K-Y, Parat M-O, Shaw PN, Falconer JR (2017) Solvent supercritical fluid technologies to extract bioactive compounds from natural sources: a review. Molecules 22:1186-1208

82. Kehili M, Schmidt LM, Reynolds W, Zammel A, Zetzl C, Smirnova I, Allouche N, Sayadi S (2016) Biorefinery cascade processing for creating added value on tomato industrial by-products from Tunisia. Biotechnol Biofuels 9:261

83. Pavlić B, Đurković AV, Vladić J, Gavarić A, Zeković Z, Tepić A, Vidović S (2016) Extraction of minor compounds (chlorophylls and carotenoids) from yarrow-rose hip mixtures by traditional versus green technique. J Food Process Eng 39:418-424

84. Gumba RE, Saallah S, Misson M, Ongkudon CM, Anton A (2016) Green biodiesel production: a review on feedstock, catalyst, monolithic reactor, and supercritical fluid technology. Biofuel Res J $3: 431-447$

85. Jokić S, Bijuk M, Aladić K, Bilić M, Molnar M (2016) Optimisation of supercritical $\mathrm{CO}_{2}$ extraction of grape seed oil using response surface methodology. Int J Food Sci Technol 51:403-410

86. Cavalcanti RN, Albuquerque CLC, Meireles MAA (2016) Supercritical $\mathrm{CO}_{2}$ extraction of cupuassu butter from defatted seed residue: experimental data, mathematical modeling and cost of manufacturing. Food Bioprod Process 97:48-62

87. Marto J, Gouveia LF, Chiari BG, Paiva A, Isaac V, Pinto P, Simões P, Almeida AJ, Ribeiro HM (2016) The green generation of sunscreens: using coffee industrial sub-products. Ind Crops Prod 80:93-100

88. Oliveira DA, Angonese M, Gomes C, Ferreira SRS (2016) Valorization of passion fruit (Passiflora edulis sp.) by-products: sustainable recovery and biological activities. J Supercrit Fluids 111:55-62

89. Viganó J, da Machado APF, Martínez J (2015) Sub- and supercritical fluid technology applied to food waste processing. J Supercrit Fluids 96:272-286

90. Lee KT, Lim S, Pang YL, Ong HC, Chong WT (2014) Integration of reactive extraction with supercritical fluids for process intensification of biodiesel production: prospects and recent advances. Prog Energy Combust Sci 45:54-78

91. Ribeiro H, Marto J, Raposo S, Agapito M, Isaac V, Chiari BG, Lisboa PF, Paiva A, Barreiros S, Simões P (2013) From coffee industry waste materials to skin-friendly products with improved skin fat levels. Eur J Lipid Sci Technol 115:330-336

92. Xynos N, Papaefstathiou G, Psychis M, Argyropoulou A, Aligiannis N, Skaltsounis AL (2012) Development of a green extraction procedure with super/subcritical fluids to produce extracts enriched in oleuropein from olive leaves. J Supercrit Fluids 67:89-93

93. Co M, Fagerlund A, Engman L, Sunnerheim K, Sjöberg PJ, Turner C (2012) Extraction of antioxidants from Spruce (Picea abies) bark using eco-friendly solvents. Phytochem Anal 23:1-11 
94. Tello J, Viguera M, Calvo L (2011) Extraction of caffeine from Robusta coffee (Coffea canephora var. Robusta) husks using supercritical carbon dioxide. J Supercrit Fluids 59:53-60

95. Budarin VL, Shuttleworth PS, Dodson JR, Hunt AJ, Lanigan B, Marriott R, Milkowski KJ, Wilson AJ, Breeden SW, Fan J, Sin EHK, Clark JH (2011) Use of green chemical technologies in an integrated biorefinery. Energy Environ Sci 4:471-479

96. İçen H, Gürü M (2010) Effect of ethanol content on supercritical carbon dioxide extraction of caffeine from tea stalk and fiber wastes. J Supercrit Fluids 55:156-160

97. Seabra IJ, Braga MEM, Batista MT, de Sousa HC (2010) Effect of solvent $\left(\mathrm{CO}_{2} / \mathrm{ethanol} / \mathrm{H}_{2} \mathrm{O}\right)$ on the fractionated enhanced solvent extraction of anthocyanins from elderberry pomace. J Supercrit Fluids 54:145-152

98. Wu H, Hu W, Zhang Y, Huang L, Zhang J, Tan S, Cai X, Xal Liao (2016) Effect of oil extraction on properties of spent coffee ground-plastic composites. J Mater Sci 51:10205-10214

99. İçen H, Gürü M (2009) Extraction of caffeine from tea stalk and fiber wastes using supercritical carbon dioxide. J Supercrit Fluids 50:225-228

100. Tian Y, Wang Y, Ma Y, Zhu P, He J, Lei J (2017) Optimization of subcritical water extraction of resveratrol from grape seeds by response surface methodology. Appl Sci 7(4):321

101. Ahmadian-Kouchaksaraie Z, Niazmand R, Najafi MN (2016) Optimization of the subcritical water extraction of phenolic antioxidants from Crocus sativus petals of saffron industry residues: BoxBehnken design and principal component analysis. Innov Food Sci Emerg Technol 36:234-244

102. Abdelmoez W, Ashour E, Naguib SM (2015) A review on green trend for oil extraction using subcritical water technology and biodiesel production. J Oleo Sci 64:467-478

103. Ravber M, Knez Ž, Škerget M (2015) Simultaneous extraction of oil- and water-soluble phase from sunflower seeds with subcritical water. Food Chem 166:316-323

104. Shalmashi A, Abedi M, Golmohammad F, Eikani MH (2009) Isolation of caffeine from tea waste using subcritical water extraction. J Food Process Eng 33:701-711

105. Pourali O, Asghari FS, Yoshida H (2010) Production of phenolic compounds from rice bran biomass under subcritical water conditions. Chem Eng J 160:259-266

106. Pourali O, Asghari FS, Yoshida H (2009) Sub-critical water treatment of rice bran to produce valuable materials. Food Chem 115:1-7

107. Liew SQ, Chin NL, Yusof YA, Sowndhararajan K (2016) Comparison of acidic and enzymatic pectin extraction from passion fruit peels and its gel properties. J Food Process Eng 39:501-511

108. Nath P, Kaur C, Rudra SG, Varghese E (2016) Enzyme-assisted extraction of carotenoid-rich extract from red capsicum (Capsicum annuum). Agric Res 5:193-204

109. Patil PD, Rao CR, Wasif AI, Anekar SV, Nagla JR (2015) Cashew-nut husk natural dye extraction using Taguchi optimization: green chemistry approach. J Sci Ind Res (India) 74:512-517

110. Madeira JV, Macedo GA (2015) Simultaneous extraction and biotransformation process to obtain high bioactivity phenolic compounds from Brazilian citrus residues. Biotechnol Prog 31:1273-1279

111. Mushtaq M, Sultana B, Bhatti HN, Asgher M (2014) Optimization of enzyme-assisted revalorization of sweet lime (Citrus limetta Risso) peel into phenolic antioxidants. BioResources 9:6153-6165

112. Cuccolini S, Aldini A, Visai L, Daglia M, Ferrari D (2013) Environmentally friendly lycopene purification from tomato peel waste: enzymatic-assisted aqueous extraction. J Agric Food Chem 61:1646-1651

113. Zykwinska A, Boiffard MH, Kontkanen H, Buchert J, Thibault JF, Bonnin E (2008) Extraction of green labeled pectins and pectic oligosaccharides from plant byproducts. J Agric Food Chem 56:8926-8935

114. Zarevúcka M, Wimmer Z (2008) Plant products for pharmacology: application of enzymes in their transformations. Int J Mol Sci 9:2447-2473

115. Manzato L, Rabelo LCA, de Souza SM, da Silva CG, Sanches EA, Rabelo D, Mariuba LAM, Simonsen J (2017) New approach for extraction of cellulose from tucumã's endocarp and its structural characterization. J Mol Struct 1143:229-234

116. Dhamole PB, Chavan S, Patil RG, Feng H, Bule M, Kinninge P (2016) Extraction of p-coumaric acid from agricultural residues and separation using "sugaring out". Korean J Chem Eng 33:1860-1864

117. Zhang C, Van Krimpen MM, Sanders JPM, Bruins ME (2016) Improving yield and composition of protein concentrates from green tea residue in an agri-food supply chain: effect of pre-treatment. Food Bioprod Process 100:92-101 
118. Rahman MM, Ho K, Netravali AN (2015) Bio-based polymeric resin from agricultural waste, neem (Azadirachta indica) seed cake, for green composites. J Appl Polym Sci 132:1-11

119. Zhang C, Sanders JPM, Xiao TT, Bruins ME (2015) How does alkali aid protein extraction in green tea leaf residue: a basis for integrated biorefinery of leaves. PLoS One 10:e0133046

120. Mudassar HR, Melin K, Koskinen J (2014) Production of carboxylic acids from alkaline pretreatment byproduct of softwood. Cellul Chem Technol 48:835-842

121. Diamanti AC, Igoumenidis PE, Mourtzinos I, Yannakopoulou K, Karathanos VT (2017) Green extraction of polyphenols from whole pomegranate fruit using cyclodextrins. Food Chem 214:61-66

122. Das AM, Hazarika MP, Goswami M, Yadav A, Khound P (2016) Extraction of cellulose from agricultural waste using Montmorillonite $\mathrm{K}-10 / \mathrm{LiOH}$ and its conversion to renewable energy: biofuel by using Myrothecium gramineum. Carbohydr Polym 141:20-27

123. Cabrera MN, Arrosbide MF, Franzoni P, Cassella N (2016) Integrated forest biorefineries: green liquor extraction in eucalyptus wood prior to kraft pulping. Biomass Convers Biorefin 6:465-474

124. Xavier L, Freire MS, Vidal-Tato I, González-Álvarez J (2014) Aqueous two-phase systems for the extraction of phenolic compounds from eucalyptus (Eucalyptus globulus) wood industrial wastes. J Chem Technol Biotechnol 89:1772-1778

125. Elksibi I, Haddar W, Ticha MB, Gharbi R, Mhenni MF (2014) Development and optimisation of a non conventional extraction process of natural dye from olive solid waste using response surface methodology (RSM). Food Chem 161:345-352

126. Avinc O, Celik A, Gedik G, Yavas A (2013) Natural dye extraction from waste barks of Turkish red pine (Pinus brutia Ten.) timber and eco-friendly natural dyeing of various textile fibers. Fibers Polym 14:866-873

127. Sun-Waterhouse D, Wang W, Waterhouse GIN, Wadhwa SS (2013) Utilisation potential of feijoa fruit wastes as ingredients for functional foods. Food Bioprocess Technol 6:3441-3455

128. Babkin VA, Malkov YA, Medvedeva EN, Trofimova NN, Ivanova NV (2012) An eco-friendly technology for polysaccharide production from logging and sawing waste. Russ $\mathrm{J}$ Gen Chem 82:955-962

129. Bertaud F, Tapin-Lingua S, Pizzi A, Navarrete P, Petit-Conil M (2012) Development of green adhesives for fibreboard manufacturing, using tannins and lignin from pulp mill residues. Cellul Chem Technol 46:7-8

130. Kim JH, Pan JH, Heo W, Lee H, Kwon EG, Lee H-G, Shin DH, Liu RH, Kim YJ (2010) Effects of cellulase from Aspergillus niger and solvent pretreatments on the extractability of organic green tea waste. J Agric Food Chem 58:10747-10751

131. Feng X, Song H, Dong B, Yang Y, Yao S (2017) Sequential extraction and separation using ionic liquids for stilbene glycoside and anthraquinones in Polygonum multiflorum. J Mol Liq 241:27-36

132. Li D, Qian Y, Tian YJ, Yuan SM, Wei W, Wang G (2017) Optimization of ionic liquid-assisted extraction of biflavonoids from Selaginella doederleinii and evaluation of its antioxidant and antitumor activity. Molecules 22(4):586

133. Larriba M, Omar S, Navarro P, García J, Rodríguez F, Gonzalez-Miquel M (2016) Recovery of tyrosol from aqueous streams using hydrophobic ionic liquids: a first step towards developing sustainable processes for olive mill wastewater (OMW) management. RSC Adv 6:18751-18762

134. Yao S, Yang Y-Y, Song H, Wang Y, Wan H-Q (2015) Quantitative industrial analysis of lignocellulosic composition in typical agro-residues and extraction of inner hemicelluloses with ionic liquid. J Sci Ind Res (India) 74:58-63

135. Achinivu EC, Howard RM, Li G, Gracz H, Henderson WA (2014) Lignin extraction from biomass with protic ionic liquids. Green Chem 16:1114-1119

136. Wang T, Jiao J, Gai QY, Wang P, Guo N, Niu LL, Fu YJ (2017) Enhanced and green extraction polyphenols and furanocoumarins from Fig (Ficus carica L.) leaves using deep eutectic solvents. J Pharm Biomed Anal 145:339-345

137. Liu Y, Chen W, Xia Q, Guo B, Wang Q, Liu S, Liu Y, Li J, Yu H (2017) Efficient cleavage of lignin-carbohydrate complexes and ultrafast extraction of lignin oligomers from wood biomass by microwave-assisted treatment with deep eutectic solvent. Chemsuschem 10(8):1692-1700

138. Jeong KM, Zhao J, Jin Y, Heo SR, Han SY, Yoo DE, Lee J (2015) Highly efficient extraction of anthocyanins from grape skin using deep eutectic solvents as green and tunable media. Arch Pharm Res 38:2143-2152 
139. Basset C, Kedidi S, Barakat A (2016) Chemical-and solvent-free mechanophysical fractionation of biomass induced by tribo-electrostatic charging: separation of proteins and lignin. ACS Sustain Chem Eng 4:4166-4173

140. Oliveira CS, Gomes FS, Constant LS, Silva LF, Godoy RL, Tonon RV, Cabral LM (2016) Integrated membrane separation processes aiming to concentrate and purify lycopene from watermelon juice. Innov Food Sci Emerg Technol 38:149-154

141. Ward DP, Cárdenas-Fernández M, Hewitson P, Ignatova S, Lye GJ (2015) Centrifugal partition chromatography in a biorefinery context: separation of monosaccharides from hydrolysed sugar beet pulp. J Chromatogr A 1411:84-91

142. Roselló-Soto E, Koubaa M, Moubarik A, Lopes RP, Saraiva JA, Boussetta N, Grimi N, Barba FJ (2015) Emerging opportunities for the effective valorization of wastes and by-products generated during olive oil production process: non-conventional methods for the recovery of high-added value compounds. Trends Food Sci Technol 45:296-310

143. Wang L, Weller CL (2006) Recent advances in extraction of nutraceuticals from plants. Trends Food Sci Technol 17(6):300-312

144. Parajuli R, Dalgaard T, Jørgensen U, Adamsen APS, Knudsen MT, Birkved M, Gylling M, Schjørring JK (2015) Biorefining in the prevailing energy and materials crisis: a review of sustainable pathways for biorefinery value chains and sustainability assessment methodologies. Renew Sustain Energy Rev 43:244-263

145. Koubaa M, Lepreux L, Barba FJ, Mhemdi H, Vorobiev E (2017) Gas-assisted mechanical expression (GAME) for the selective recovery of lipophilic and hydrophilic compounds from olive kernel. J Clean Prod 166:387-394

146. Castro-Puyana M, Marina ML, Plaza M (2017) Water as green extraction solvent: principles and reasons for its use. Curr Opin Green Sustain Chem 5:31-36

147. Kusuma HS, Mahfud M (2017) Comparison of conventional and microwave-assisted distillation of essential oil from Pogostemon cablin leaves: analysis and modelling of heat and mass transfer. $\mathrm{J}$ Appl Res Med Aromat Plants 4:55-65

148. Rosa R, Tassi L, Orteca G, Saladini M, Villa C, Veronesi P, Leonelli C, Ferrari E (2017) Process intensification by experimental design application to microwave-assisted extraction of phenolic compounds from Juglans regia L. Food Anal Methods 10(3):575-586

149. Zhu Y, Song H, Zhang X, Chen C, Zhao S, Ge F, Liu D (2017) Recovery of flavonoids from walnuts de-pellicle wastewater with macroporous resins and evaluation of antioxidant activities in vitro. J Food Process Eng 40:1

150. Vardanega R, Carvalho PI, Albarelli JQ, Santos DT, Meireles MAA (2017) Techno-economic evaluation of obtaining Brazilian ginseng extracts in potential production scenarios. Food Bioprod Process 101:45-55

151. Chemat F, Rombaut N, Sicaire AG, Meullemiestre A, Fabiano-Tixier AS, Abert-Vian M (2017) Ultrasound-assisted extraction of food and natural products. Mechanisms, techniques, combinations, protocols and applications. A review. Ultrason Sonochem 34:540-560

152. Puga H, Alves RC, Costa AS, Vinha AF, Oliveira MBP (2017) Multi-frequency multimode modulated technology as a clean, fast, and sustainable process to recover antioxidants from a coffee byproduct. J Clean Prod 168:14-21

153. Pavlić B, Naffati A, Hojan T, Vladić J, Zeković Z, Vidović S (2017) Microwave-assisted extraction of wild apple fruit dust-production of polyphenol-rich extracts from filter tea factory by-products. J Food Process Eng 40:4

154. Alañón ME, Alarcón M, Marchante L, Díaz-Maroto MC, Pérez-Coello MS (2017) Extraction of natural flavorings with antioxidant capacity from cooperage by-products by green extraction procedure with subcritical fluids. Ind Crops Prod 103:222-232

155. Arevalo-Gallegos A, Ahmad Z, Asgher M, Parra-Saldivar R, Iqbal HM (2017) Lignocellulose: a sustainable material to produce value-added products with a zero waste approach - a review. Int $\mathrm{J}$ Biol Macromol 99:308-318

156. Lozano-Sánchez J, Bendini A, Di Lecce G, Valli E, Gallina Toschi T, Segura-Carretero A (2017) Macro and micro functional components of a spreadable olive by-product (pâté) generated by new concept of two-phase decanter. Eur J Lipid Sci Technol 119:1

157. Klinjapo R, Klinjapo R, Areerat K, Areerat K, Sutthirak P, Sutthirak P (2017) Study effect of natural extracts on the antioxidant activity in pork balls. Br Food J 119(10):2217-2228 
158. Pinela J, Prieto MA, Barreiro MF, Carvalho AM, Oliveira MBP, Curran TP, Ferreira IC (2017) Valorisation of tomato wastes for development of nutrient-rich antioxidant ingredients: a sustainable approach towards the needs of the today's society. Innov Food Sci Emerg Technol 41:160-171

159. García-Pérez JS, Robledo-Padilla F, Cuellar-Bermudez SP, Arévalo-Gallegos A, Parra-Saldivar R, Zavala-Yoe R, Ramirez-Mendoza RA, Iqbal HMN (2017) Thermodynamics and statistical correlation between supercritical- $\mathrm{CO}_{2}$ fluid extraction and bioactivity profile of locally available Mexican plants extracts. J Supercrit Fluids 122:27-34

160. Cerempei A, Mureşan EI, Cimpoeşu N, Carp-Cărare C, Rimbu C (2016) Dyeing and antibacterial properties of aqueous extracts from quince (Cydonia oblonga) leaves. Ind Crops Prod 94:216-225

161. Rodríguez-López L, Vecino X, Barbosa-Pereira L, Moldes AB, Cruz JM (2016) A multifunctional extract from corn steep liquor: antioxidant and surfactant activities. Food Funct 7:3724-3732

162. Wildermuth SR, Young EE, Were LM (2016) Chlorogenic acid oxidation and its reaction with sunflower proteins to form green-colored complexes. Compr Rev Food Sci Food Saf 15:829-843

163. Amiri-Rigi A, Abbasi S, Scanlon MG (2016) Enhanced lycopene extraction from tomato industrial waste using microemulsion technique: optimization of enzymatic and ultrasound pre-treatments. Innov Food Sci Emerg Technol 35:160-167

164. Barba FJ, Zhu Z, Koubaa M, Sant'Ana AS, Orlien V (2016) Green alternative methods for the extraction of antioxidant bioactive compounds from winery wastes and by-products: a review. Trends Food Sci Technol 49:96-109

165. Ravber M, Knez Ž, Škerget M (2015) Isolation of phenolic compounds from larch wood waste using pressurized hot water: extraction, analysis and economic evaluation. Cellulose 22:3359-3375

166. Amiri-Rigi A, Abbasi S (2016) Microemulsion-based lycopene extraction: effect of surfactants, cosurfactants and pretreatments. Food Chem 197:1002-1007

167. Lucas-Torres C, Lorente A, Cabañas B, Moreno A (2016) Microwave heating for the catalytic conversion of melon rind waste into biofuel precursors. J Clean Prod 138:59-69

168. Papaioannou EH, Liakopoulou-Kyriakides M, Karabelas AJ (2016) Natural origin lycopene and its "green" downstream processing. Crit Rev Food Sci Nutr 56:686-709

169. Rajabinejad H, Bucişcanu I-I, Maier S-S (2016) Practical ways of extracting keratin from keratinous wastes and by-products: a review. Environ Eng Manag J 15:1131-1147

170. Sixt M, Koudous I, Strube J (2016) Process design for integration of extraction, purification and formulation with alternative solvent concepts. C R Chim 19:733-748

171. Delisi R, Saiano F, Pagliaro M, Ciriminna R (2016) Quick assessment of the economic value of olive mill waste water. Chem Cent J 10:63

172. Suteu D, Zaharia C, Popovici C, Malutan T, Rusu L, Tabacaru L (2016) Wood waste as a renewable source of energy. Environ Eng Manag J 15:665-673

173. Talmaciu AI, Volf I, Popa VI (2015) A comparative analysis of the "green" techniques applied for polyphenols extraction from bioresources. Chem Biodivers 12:1635-1651

174. Katsampa P, Valsamedou E, Grigorakis S, Makris DP (2015) A green ultrasound-assisted extraction process for the recovery of antioxidant polyphenols and pigments from onion solid wastes using Box-Behnken experimental design and kinetics. Ind Crops Prod 77:535-543

175. Ramamoorthy SK, Skrifvars M, Persson A (2015) A review of natural fibers used in biocomposites: plant, animal and regenerated cellulose fibers. Polym Rev 55:107-162

176. Madeira Junior JV, Teixeira CB, Macedo GA (2015) Biotransformation and bioconversion of phenolic compounds obtainment: an overview. Crit Rev Biotechnol 35:75-81

177. Fan R, Yuan F, Wang N, Gao Y, Huang Y (2015) Extraction and analysis of antioxidant compounds from the residues of Asparagus officinalis L. J Food Sci Technol 52:2690-2700

178. Christiaens S, Uwibambe D, Uyttebroek M, Van Droogenbroeck B, Van Loey AM, Hendrickx ME (2015) Pectin characterisation in vegetable waste streams: a starting point for waste valorisation in the food industry. LWT Food Sci Technol 61:275-282

179. Vauchel P, Galván D’Alessandro L, Dhulster P, Nikov I, Dimitrov K (2015) Pilot scale demonstration of integrated extraction-adsorption eco-process for selective recovery of antioxidants from berries wastes. J Food Eng 158:1-7

180. Hamad F, Mubofu E (2015) Potential biological applications of bio-based anacardic acids and their derivatives. Int J Mol Sci 16:8569-8590

181. Sandei L, Bandini M, Del Rio D (2015) Recovery of tomato bioactive compounds through a biocompatible and eco-sustainable new technology for the production of enriched "nutraceutical tomato products". Acta Hortic 1081:345-351 
182. Shitu A, Izhar S, Tahir TM (2015) Sub-critical water as a green solvent for production of valuable materials from agricultural waste biomass: a review of recent work. Glob J Environ Sci Manag $1: 255-264$

183. Attard TM, McElroy CR, Rezende CA, Polikarpov I, Clark JH, Hunt AJ (2015) Sugarcane waste as a valuable source of lipophilic molecules. Ind Crops Prod 76:95-103

184. Nagel A, Mix K, Kuebler S, Bogner H, Kienzle S, Elstner P, Carle R, Neidhart S (2015) The arabinogalactan of dried mango exudate and its co-extraction during pectin recovery from mango peel. Food Hydrocoll 46:134-143

185. Low JH, Rahman WAWA, Jamaluddin J (2015) The influence of extraction parameters on spent coffee grounds as a renewable tannin resource. J Clean Prod 101:222-228

186. Mena P, Ascacio-Valdés JA, Gironés-Vilaplana A, Del Rio D, Moreno DA, García-Viguera C (2014) Assessment of pomegranate wine lees as a valuable source for the recovery of (poly) phenolic compounds. Food Chem 145:327-334

187. Mamma D, Christakopoulos P (2014) Biotransformation of citrus by-products into value added products. Waste Biomass Valoriz 5:529-549

188. Jenkins RW, Stageman NE, Fortune CM, Chuck CJ (2014) Effect of the type of bean, processing, and geographical location on the biodiesel produced from waste coffee grounds. Energy Fuels 28:1166-1174

189. Zakikhani P, Zahari R, Sultan MTH, Majid DL (2014) Extraction and preparation of bamboo fibrereinforced composites. Mater Des 63:820-828

190. Oliveira AL, Destandau E, Fougère L, Lafosse M (2014) Isolation by pressurised fluid extraction (PFE) and identification using CPC and HPLC/ESI/MS of phenolic compounds from Brazilian cherry seeds (Eugenia uniflora L.). Food Chem 145:522-529

191. Araniti F, Marrelli M, Lupini A, Mercati F, Statti GA, Abenavoli MR (2014) Phytotoxic activity of Cachrys pungens Jan, a Mediterranean species: separation, identification and quantification of potential allelochemicals. Acta Physiol Plant 36:1071-1083

192. Schnitzer M, Monreal CM, Powell EE (2014) Wheat straw biomass: a resource for high-value chemicals. J Environ Sci Heal Part B 49:51-67

193. Arvayo-Enríquez H, Mondaca-Fernández I, Gortárez-Moroyoqui P, López-Cervantes J, RodríguezRamírez R (2013) Carotenoids extraction and quantification: a review. Anal Methods 5:2916

194. Simões J, Nunes FM, Domingues MR, Coimbra MA (2013) Extractability and structure of spent coffee ground polysaccharides by roasting pre-treatments. Carbohydr Polym 97:81-89

195. Royer M, Kinuani N, Diouf PN (2013) Forest extractives, the 4th pathway of the Forest biorefinery concept. J FOR 3:32-41

196. Fameau A-L, Gaillard C, Marion D, Bakan B (2013) Interfacial properties of functionalized assemblies of hydroxy-fatty acid salts isolated from fruit tomato peels. Green Chem 15:341-346

197. Shahid-ul-Islam Shahid M, Mohammad F (2013) Perspectives for natural product based agents derived from industrial plants in textile applications-a review. J Clean Prod 57:2-18

198. Panusa A, Zuorro A, Lavecchia R, Marrosu G, Petrucci R (2013) Recovery of natural antioxidants from spent coffee grounds. J Agric Food Chem 61:4162-4168

199. Tan HP, Li HP, Song H, Xu WP, Guan C, Ran LP (2012) A novel way of separation and preparation noncaffeine tea polyphenols from green tea waste. Adv Mater Res 550-553:1875-1880

200. Durante M, Lenucci MS, Rescio L, Mita G, Caretto S (2012) Durum wheat by-products as natural sources of valuable nutrients. Phytochem Rev 11:255-262

201. Liew MS, Shamsuddin AH, Yew GZ (2011) Fiber resin matrix composites: nature's gift. WIT Trans Ecol Environ 148:131-140

202. Clark JH, Fitzpatrick EM, Macquarrie DJ, Pfaltzgraff LA, Sherwood J (2012) p-Cymenesulphonic acid: an organic acid synthesised from citrus waste. Catal Today 190:144-149

203. Yuda N, Tanaka M, Suzuki M, Asano Y, Ochi H, Iwatsuki K (2012) Polyphenols extracted from black tea (Camellia sinensis) residue by hot-compressed water and their inhibitory effect on pancreatic lipase in vitro. J Food Sci 77:H254-H261

204. Li ZJ, Wei Z, Xiao W, Wang J, Wu FA (2012) Recovery of tea polyphenols from green tea waste by liquid-liquid extraction. Adv Mater Res 396-398:1592-1595

205. Li CP, Wang LL, Jin ZS, Tang L (2012) Study on the extraction technique of poly-methoxyflavonoids from citrus peels by using response surface methodology. Adv Mater Res 560-561:544-549

206. Périno-Issartier S, Zill-e-Huma Abert-Vian M, Chemat F (2011) Solvent free microwave-assisted extraction of antioxidants from sea buckthorn (Hippophae rhamnoides) food by-products. Food Bioprocess Technol 4:1020-1028 
207. Lozano-Sánchez J, Giambanelli E, Quirantes-Piné R, Cerretani L, Bendini A, Segura-Carretero A, Fernández-Gutiérrez A (2011) Wastes generated during the storage of extra virgin olive oil as a natural source of phenolic compounds. J Agric Food Chem 59:11491-11500

208. Chemat-Djenni Z, Ferhat MA, Tomao V, Chemat F (2010) Carotenoid extraction from tomato using a green solvent resulting from orange processing waste. J Essent Oil Bear Plants 13:139-147

209. Tsukayama M, Sasaki T, Yamamoto K, Kawamura Y, Ichikawa R (2010) Microwave-assisted extraction and methylation of useful flavones from waste peels of citrus sudachi. Nippon Shokuhin Kagaku Kogaku Kaishi 57:427-433

210. Vieira MA, Maraschin M, Pagliosa CM, Podestá R, De Simas KN, Rockenbach II, Amboni RDMC, Amante ER (2010) Phenolic acids and methylxanthines composition and antioxidant properties of mate (Ilex paraguariensis) residue. J Food Sci 75:C280-C285

211. Sun-Waterhouse D, Wen I, Wibisono R, Melton LD, Wadhwa S (2009) Evaluation of the extraction efficiency for polyphenol extracts from by-products of green kiwifruit juicing. Int J Food Sci Technol 44:2644-2652

212. Bhat R, Khalil HPSA, Karim AA (2009) Exploring the antioxidant potential of lignin isolated from black liquor of oil palm waste. C R Biol 332:827-831

213. Wijngaard H, Brunton N (2009) The optimization of extraction of antioxidants from apple pomace by pressurized liquids. J Agric Food Chem 57:10625-10631

214. Liang H, Li C, Yuan Q, Vriesekoop F (2007) Separation and purification of sulforaphane from broccoli seeds by solid phase extraction and preparative high-performance liquid chromatography. J Agric Food Chem 55:8047-8053

215. Senol A, Aydin A (2006) Solid-liquid extraction of caffeine from tea waste using battery type extractor: process optimization. J Food Eng 75:565-573 